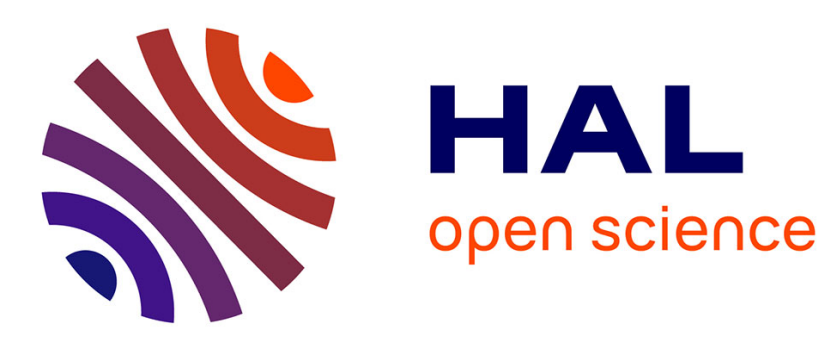

\title{
Atoms of negation: An outside-in micro-parametric approach to negative concord
}

\author{
Viviane Deprez
}

\section{To cite this version:}

Viviane Deprez. Atoms of negation: An outside-in micro-parametric approach to negative concord. The Evolution of Negation: Beyond the Jespersen Cycle, Mouton de Gruyter, pp.221-272, 2012. hal00925894

\section{HAL Id: hal-00925894 \\ https://hal.science/hal-00925894}

Submitted on 8 Jan 2014

HAL is a multi-disciplinary open access archive for the deposit and dissemination of scientific research documents, whether they are published or not. The documents may come from teaching and research institutions in France or abroad, or from public or private research centers.
L'archive ouverte pluridisciplinaire HAL, est destinée au dépôt et à la diffusion de documents scientifiques de niveau recherche, publiés ou non, émanant des établissements d'enseignement et de recherche français ou étrangers, des laboratoires publics ou privés. 


\title{
Atoms of negation: An outside-in micro-parametric approach to negative concord
}

\author{
Viviane Déprez
}

\section{Contrasting theoretical outlooks: Inside-out vs. outside-in perspectives}

In this paper, two core perspectives on variation in negative concord are distinguished, one that focuses on the syntactic nature of negation as the central factor of variation, and one that focuses on the internal make-up of the negative dependent terms, the n-words. The first part of the paper outlines the different predictions that emerge from these differing perspectives. The second part provides evidence in support of the latter perspective.

Recent work in the Minimalist framework has revamped the classic idea pioneered by the nineteenth century linguist Otto Jespersen that there is "a strong correlation between the syntactic status of the sentential negation marker and the phenomenon of negative concord" (Zeijlstra 2008:1). For Jespersen, negative relations were subject to a cycle largely conditioned by the syntactic nature of the sentential negation marker as weak or strong. Similarly, with their core reliance on the strength or interpretability and weakness or uninterpretability of negative features, Minimalist approaches such as Zeijlstra's (2008) (see also Zeiljstra 2004; Willis 2004; Penka 2007), which cast negative concord as a prime case of an Agree relation à la Chomksy $(2000,2001)$, operate a terminological and conceptual fusion with the classic Jespersen view. Like Jespersen's, these approaches are macro-parametric in nature, as they seek to formulate "a single theory of negative concord, that also predicts the parametric variation between negative concord languages (strict vs. non-strict NC languages) as well as the variation between NC languages and DN languages" (Zejlstra 2008: 3). But furthering Jespersen, these perspectives extend the cycle's purview beyond the syntax of negation proper to include negative dependencies in a broader sense, i.e. relations between sentential negation and dependent nominal terms.

In this paper, this neo-classic macro-parametric view to negative concord variation is contrasted with a distinct micro-parametric approach to $\mathrm{NC}$ whose core idea is to move away from the classic and neo-classic Jespersonian focus on the syntactic properties of the sentential negative 
1 marker to center instead on the syntactic properties of the n-words them2 selves. This approach takes the negative dependent expressions as key 3 factors of variation in negative concord systems (Corblin, de Swart \& 4 Déprez 2004; Déprez 1997, 1999, 2000; Déprez and Martineau 2004; 5 Tovena, Déprez, and Jayez 2004; Londhal \& Haegeman 2010). At the heart 6 of this micro-parametric approach is the claim that the diverse properties of 7 negative concord observable in a great variety of languages, synchronically 8 or and diachronically, primarily derive from the internal micro-morpho9 syntax and resulting differences between participating negative expressions 
1 geneity of negative systems in particular languages. It is further argued

that this also has important consequences from a diachronic point of view. In its second part, the paper then endeavours to demonstrate that, within a restricted empirical domain, the predictions of the micro-parametric approach are clearly verified.

The paper is structured as follows: Section 1.2. contrasts the theoretical predictions of a Jespersonian neo-classic inside-out macro-parametric model of negative concord, like that of Zeijsltra (2008), with those of our micro-parametric outside-in approach for both synchronic comparative linguistic variation and diachronic language change. Section 3 presents comparative data from contemporary European French and French-based Creoles that underscore the importance of inner language diversity expected under the micro-parametric approach, but not under a macro-parametric model. Section 4 offers a detailed study of the internal structure of the French n-word rien and personne and of their historical evolution as a further diachronic confirmation of the importance of internal structural changes for the correlated changes in the properties of negative concord. In this section, an in-depth look at diachronic changes in the modification possibility of French n-words across time is presented that allows their internal evolution to be charted.

\subsection{Cross-linguistic variation and inner language homogeneity}

On what has been termed here a 'neo-classic inside-out perspective' on negative relations, variation in the negative concord properties of a language is expected to concur with variation in the syntactic nature of the sentential negation marker. Thus, if a given language presents a given type of sentential negation marker, then expectations are that this language should manifest a given type of negative relations quite generally. Such a perspective is common to a number of generative approaches, starting from Zanuttini (2001) up to the more recent works of Zeijlstra (2004) and subsequent publications. Concretely, for Zeiljstra (2008) for instance, a core generalization that his approach is designed to predict is that:

(2) Every language that has a negative marker $\mathrm{X}^{\circ}$ is an $\mathrm{NC}$ language (provided that n-words are present).

(Zeijlstra 2008: 17) ${ }^{1}$

1. In Zeijlstra's model, a negative $X^{0}$ is allowed to be phonetically null. This is unfortunate, because to a large extend, it quite significantly hollows out the empirical bite of this model, making it quasi impossible to be empirically contradicted. Indeed, any language that manifests negative concord can in principle be claimed to have a null $\mathrm{X}^{0}$ negation, thus meeting (2), so to speak, by theoretical brute force. 
The implication here is unidirectional, as is customary with other macroparameters proposed in the literature (Baker 2008), so that if the sentential negation marker of a language $\mathrm{L}$ is not an $\mathrm{X}^{0}$, no prediction is made with respect to negative concord. Note, however, and this is fundamental, that the generalization in (2) makes sense only in so far as the notion of negative concord language can be well defined independently. Assume, for the sake of the argument, the fairly uncontroversial view that a negative concord language is a language in which negative relations generally take the characteristic shape of multiple negative marking for a single negative interpretation. What is clear then, given (2), is that a language with an $\mathrm{X}^{0}$ negation should manifest negative concord throughout. That is, inner language homogeneity with respect to negative concord, with multiple negative dependent terms interpreted as a single sentential negation, is expected. Such homogeneity must, in fact, quite simply, on Zeijlstra's perspective, be a defining criterion for what a negative concord language is, if circularity is to be avoided. What is in question, here, however, is whether such homogeneous languages are in fact ever empirically observed. ${ }^{2}$ In the realm of negative dependencies, this turns out to be, it would seem, far from obvious. If anything, after years of careful observations in the literature, what seems to be quite characteristic of languages that effectively manifest negative concord is that they regularly present a rather theoretically unsavoury patchwork of surprising inner variation. That is, languages in which a single clearly uniform type of negative dependencies prevails do not seem that common; what detailed empirical linguistic observations have commonly unearthed within particular languages are rather mixed systems in which there are some negative relations that present a certain type of linguistic behaviour along with others that present distinct ones. To wit, Italian or Spanish, which are treated as negative concord languages in Zeijlstra (2004 \& following), but also have distinct NPI expressions that function quite differently (Zanuttini 1991; Laka 1990). Another such language is Greek, where negative dependent terms partition into

2. The question is put in the strongest terms here, but note that a weaker form would be sufficient to raise doubts about the typological predictions of (2). Indeed, even if a few truly homogeneous NC languages could be found, with all the negative relations taking the same shape, this would still not show that most languages allowing $\mathrm{NC}$ are or this sort, as the generalization in (2) leads us to expect. The existence of only a few truly homogenous languages is compatible with a micro-parametric approach, if it can be shown that all the $\mathrm{n}$-expressions share crucial internal structures. 
two sets with distinct negative relations depending on their stress patterns, and which has additional NPI expressions that fall under different licensing conditions (Giannakidou 1997). Yet another such language is SerboCroatian, where two sets of negative dependent terms (ni-NPIs vs $i$-NPIs) with different distributions and licensing conditions are distinguished (see Progovac 1994 among others). ${ }^{3}$ Finally, even American English, which, according to Zeijlstra (2004), is a clear example of non-NC language, can manifest unquestionable examples of NC. Witness the attested uses of the expression diddly squat that clearly functions as a negative in (3a), but just as clearly manifests concord when in co-presence with negation in (3b), or with another negative quantifier as in (3c):

(3) a. Alan Cumming To Obama: You've Done Diddly Squat' For Gay Rights.

(http://www.thefreelibrary.com/ Oct 25, 2010)

b. Those shiny cars won't mean diddly squat when you die. (http://www.urbandictionary.com/ Oct 25, 2010)

c. Nobody knows squat about your topic. (= Nobody knows anything)

(Internet data cited in Postal 2004)

In short, in the realm of negative relations, within-language diversity appears to be more often the rule than the exception. From a general macroparametric inside-out perspective such as the one laid out in (2), the question that arises is: what should be made of such common inner-language variation for languages in which the sentential negation form stays reasonably constant? Faced with an inner-language diverse reality, should one conclude that either we do not have a bona-fide negative concord language even if some instances of negative concord can be observed, or if the given language is classified as a negative concord one, are we then not compelled to concede that at least some negative relations fail to consistently behave as predicted by the syntactic nature of sentential negation? In sum, what

3. Although Progovac's (1994) study is limited to characterizing the licensing conditions of negative dependencies in Serbo-Croatian, she wonders about the source of the variation she observes in the conclusion of her chapter on language variation as follows: "If negative polarity items are homogenous class, why should they select different (LF) landing sites? First of all, they might not be a homogenous class at all. [...]. Perhaps the clues might be sought in their morphological properties." (Progovac 1994: 90). The fruitfulness of this suggested approach is precisely what we aim at defending here. 
1 is far from obvious from an inside-out macro-parametric perspective is 2 to see how a theory of $\mathrm{NC}$ whose determining factor is the syntactic 3 nature of sentential negation could account for a language in which dis4 tinct $n$-expressions behave differently while sentential negation, in contrast, 5 remains constant. More generally, although an inside-out perspective such 6 as Jespersen's or Zeijlstra's could well be adequately equipped to deal 7 with cross-linguistic diversity given language-internal homogeneity, inner8 language diversity, in contrast, appears to present a serious challenge to it. 9 That inner language diversity does in fact occur even in languages that fully argued and instantiated in what follows.

It is further important to note that such inner-diversity situations are precisely the ones that the micro-parametric outside-in approach to negative concord defended here is particularly well equipped to handle theoretically. Since on this micro-parametric view, it is the internal make-up of an n-expression and its interpretation at the syntax-semantic interface that centrally determines its 'external' behaviour at the sentence level, and thus ultimately, its concord properties, then n-expressions do not need, and are not predicted to be homogeneous within any given language. In other words, on our micro-parametric perspective, inner-language or dialect homogeneity across all n-expressions is not required. Yet, the appearance of inner-language or dialect homogeneity could of course occur, since it is always possible that a majority of n-expressions within a given language have comparable inner structure. Note, incidentally, that this demonstrates the ability of the outside-in micro-parametric perspective to handle situations of inner language homogeneity, should they ever arise. However, inner language homogeneity is not a necessity on this view. What is predicted instead on a micro-parametric-outside-in perspective is that $n$-expressions with a common internal make up should behave homogeneously whether within or across languages. So there is homogeneity expected here as well, but it is homogeneity of a different kind.

On the micro-parametric perspective, homogeneity across all the nexpressions within a single given language is not necessary. What is expected is homogeneity across $n$-expressions that can be shown to have the same syntactic make-up, in whichever language, dialect, or historical stage they may happen to occur. As a result, within languages, variation is not problematic for this perspective and is in fact expected whenever it can be shown that n-expressions differ significantly in their internal make up. In short, inside-out perspectives, such as Jespersen's or Zeijlstra's, which centre on the properties of sentential negation, produce expectations 
of homogeneity within languages that have a unique sentential negation marker, thereby raising the delicate question of what a (homogeneous) negative concord language should ultimately be. In contrast, the microparametric outside-in perspective produces expectations of homogeneity across types of n-expression structures, conveniently sidestepping the very delicate question of language homogeneity, characteristically an E-language perspective problem.

Within a micro-parametric approach, generalizations are defined not over negative concord E-languages, but over types of internal-structures independently of their actual proportional embodiment in particular languages, dialects, sociolects or historical stages. As a result, if the morphostructure of an n-expression were to stay constant through time, then so would its negative concord properties. In contrast, internal changes should foster changes in external behaviour and, in particular, changes in the interaction with sentential negation, which may itself well remain constant. These are the expectations under the inside-out perspective defended here, and the following discussion will detail empirical evidence gathered in support of this view.

\subsection{Historical variations}

The direction in perspective that distinguishes an inside-in macro-parametric approach from an outside-in micro-parametric model also has important consequences from a diachronic point of view. Given the focus in the former on the properties of sentential negation as a key factor of variation, it is clearly change in the nature of sentential negation that is expected to drive changes in the properties of negative relations. This is the core idea of Jespersen's negative cycle. For Jespersen, it is the (phonological) weakening of negation that calls for its reinforcement by added negative expressions. For Zeijlstra, given the principle in (2), a change in the 'weakening' syntactic status of negation, i.e. if negation becomes an $\mathrm{X}^{0}$, would also change the negative concord expectation for any given language. Unfortunately, change in the other direction, from a weakened $X^{0}$ negation, to an XP one, does not lead to any clear predictions in Zeijlstra's model. The spirit of the proposal leads to the expectation that if sentential negation changes, then negative relations will be affected. But the second part of (2) only predicts the development of negative concord in case negation is or becomes an $\mathrm{X}^{0.2}$.

Let us consider the case of French, which probably offers one of the bestdocumented examples of diachronic evolution for negation and negative 
1 dependencies. The in-depth historical and comparative dialectal research 2 on the evolution of the French negative operator ne and ne ...pas con3 ducted by Martineau \& Mougeon (2003) and Martineau \& Déprez (2004) 4 shows that changes in the sentential marker do not drive changes in the 5 nature of negative dependencies or the behaviour of n-words. By the time 6 that ne and pas had acquired their current syntactic and semantic proper7 ties, n-words still largely behaved like dependent NPIs. They therefore 8 acquired their current intrinsic negative meaning and their current nega9 tive concord properties well after ne had weakened and pas had been 10 strengthened. Pas already had the properties it has nowadays in the 11 fifteenth century, a time at which, as our work demonstrates, n-words instead quite clearly dependent on negation for their negative meaning. That is, they manifested NPI like properties. Moreover, they clearly also had distinct syntactic properties. In short, the acquired negative character of contemporary n-words, and hence of negative concord, cannot be directly triggered by the weakening of sentential negation (interpretable negation switching to uninterpretable negation or vice versa, however this is encoded) and so it appears equally misguided to assume that the properties of negative concord in contemporary French could causally result from a change in the nature of sentential negation. Strictly speaking, a principle like (2) simply appears to be unable to explain the historical rise of French negative concord, since it links negative concord to a weak $/ \mathrm{X}^{0}$ status of negation while French negative concord and n-words did not arise until ne was strengthened by the non- $\mathrm{X}^{0}$ negation pas.

Ingham's work on the diachronic replacement of nul by aucun in medieval to Middle French and in Anglo-Norman also sharply demonstrates the occurrence of changes in negative relations and n-words that are fully independent of any changes in sentential negation. In the same vein, it is equally well acknowledged that the French negation ne already resulted from the weakening of the Latin negation non and yet, it has come to no one's mind to claim that French negative concord derived from this first negative weakening. On the basis of these results (see also Martineau in this volume for a further study on the diachronic changes of sentential negation), it can thus be quite firmly concluded that, in French, the expected causal direction of an inside-out perspective, i.e. changes in sentential negation driving changes in the nature of $n$-words dependencies towards negative concord, is simply not supported by the available historical evidence. 
Interestingly, moreover, such a causal relation does not appear to be observed in the diachrony of Greek either. As explicitly noted by Kiparsky \& Condoravdi (2005b: 2) there are "numerous instantiations of the (Jespersen) cycle from Medieval to Modern Greek, but the syntax of negation stays the same". That is, changes occurred in negation dependent elements, while negation remained constant. So here, again, diachronic evidence does not support the view that it was changes in the syntactic properties of sentential negation that drove the changes in negative relations.

In contrast, if we take the outside-in perspective, defended here and in previous works, expectations are that, in negative relations, historical change should proceed from the internal morpho-structure of n-expressions to their external sentential behaviour, and not the other way around. That is, change should primarily operate from the internal micro-domain of the n-expressions to the external macro-domain of clausal negation. In other words, this view makes clear empirically verifiable predictions on the general course of historical development of negative relations positing that changes in the internal structure of n-expressions will drive changes in negative relations. Section 3.2 presents a detailed analysis of the internal changes in the structure of French n-words supporting this view. It discusses historical data on the modification of n-words. The key idea pursued here, as before (Déprez 1997, 1999, 2000, 2004) and also adopted in Roberts \& Roussou (2003), is that restructuration arose in the internal structure of French n-words as a consequence of the loss of bare noun phrases, i.e. the gradual loss of null determination in Modern French, which, as argued previously in Déprez $(2000,2005)$, is itself a consequence of the evolution of morphological number marking in French. ${ }^{4}$ In simple terms, what is defended here, as before, is that the historical change of French negative relations is in large part a consequence of the internal syntactic restructuring of its n-expressions, which was triggered by yet a distinct change in the expression of number in the language, causing the suppression of null determiners. Although changes also occurred in

4. It is thus the weakening of number marking rather than the mere existence of bare noun phrases that Déprez $(1999,2000)$ proposes as a factor of change in the internal structure of French n-words. Crucially, as discussed in detail in Déprez (1999), it would be wrong to assume, as for instance Willis (2007) mistakenly does, that the claim is that the mere existence of bare nouns should coincide with negative concord. Counterexamples to such a claim abound, as noted in Déprez (1999), with English and German being quite obviously languages in which bare NPs are possible, but negative concord supposedly is not. 
1 sentential negation, the claim is that this change is not at the root of the 2 current properties of negative concord in contemporary French.

3

\subsection{Micro vs Macro-parametric perspectives}

The points made in this section relate to more general issues on language variation and the nature of parametric distinctions. In short, following in Jespersen's footsteps, Zeijlstra's principle (2) amounts to claiming that there is a macro-parameter that distinguishes negative concord languages from non-negative concord ones, and that the formulation of this macroparameter centers on the properties of sentential negation. In contrast, the perspective defended here is that the phenomenon of negative concord arises through the convergence of micro-parametric settings that constrain the inner structure of $n$-expressions with predicted consequences on their semantics and on how they interact with sentential negation. Many approaches to negative concord have, at some level, recognized the necessity of understanding the interactions between the micro-level of negative relations, i.e. the nature of the n-expressions, and the macro-level of their effects at the sentential level. It seems, however, that the majority of approaches proposed in the recent generative literature have followed a Jespersonian perspective and focused on a macro inside-out perspective that concentrates on the syntactic or semantic properties of sentential negation as the locus of the crucial defining factors of the nature of negative concord relations. This was true also of approaches based on a NegP constituent and the Neg Criterion that sought to draw similarities between negative relations and wh-dependencies. ${ }^{5}$ It is both my hope and my conviction that looking negative relations from, so to speak, the other side of the lens, i.e. from the micro to macro outside-in perspective can but bring

5. In Déprez (1999), I provide a thorough criticism of this approach, showing that the syntactic properties that characterize negative concord relations are quite distinct from those of wh-dependencies. I demonstrate in particular that negative concord is subject to locality constraints that are much closer to those of QR than to those of wh-movement. Quite strikingly moreover, question words display an language internal homogeneity in behaviour that contrasts with the diversity found with n-words, suggesting that wh-dependencies may be more amenable to a macro-parametric variations approach than negative dependencies. That is, while it is common to find negative dependent terms that differ in behaviour within a single language, the same is not true for wh-terms. To my knowledge, it is not common to find wh-terms in a given language that must undergo wh-movement, while others must remain in situ. 
fruitful new discoveries. Although it might seem at the outset that detailed studies of the inner structure of n-expressions could bring out awareness of greater diversity than has so far been acknowledged, with the consequence of putting some previously held generalizations on shaky grounds, I am convinced that such an approach will bring in the end the clear potential of new generalizations that will deepen our level of understanding of the atomic structure of negative relations. It is as if after spending many years successfully characterizing and refining the overall syntactic properties of negative relations, it was now time to delve into their details to try to understand how the broad characteristics of these relations, which are now rather well known, could be deduced at least in part from the microstructure and inner relations of their composite elements.

\section{Testing the empirical grounds}

In this second part of the paper, empirical evidence of the importance of the inner structure of $n$-expressions is examined. We first discuss evidence of inner language diversity in a fairly strong case of a so-called 'strict negative concord language', namely Haitian Creole. We then turn to historical evidence of the evolution of the inner structure of French negative expressions. In both cases, what is emphasized is how much the inner nature of n-words matters for an understanding of their contribution to the fabric of negative relations.

\subsection{Inner language diversity and negative concord}

In previous work (Déprez 1997, 1999, 2000), negative concord systems have been distinguished on the basis of 1) the internal syntax of their n-words and 2) the semantic interface that these syntactic structures imply. It was argued that $\mathrm{n}$-words in languages like Haitian Creole (HC) occupy a low position in the functional structure of their nominal constituent, manifesting syntactic and semantic properties relating to those of bare nominals. Negative concord there involves an operator variable system in which negation binds a bare nominal variable. By contrast, in languages like French n-words are placed high in their DP, behaving syntactically like determiners with the semantics of quantificational expressions. Negative concord in this case is quite distinct and involves resumptive quantification between negative quantifiers that are syntactically and semantically parallel, as proposed for English in May (1989). These two systems instantiate polar extremes between which micro-variations unfolds Déprez 1999, 2000). 
1 Motivation for this proposal was based on the observation that although n-words share the appearance of bare nominals in both languages pesonn, anyen in $\mathrm{HC}$ and personne, rien in French - the general licensing conditions on bare $\mathrm{N}$-arguments radically differ in each, bare- arguments occurring freely in $\mathrm{HC}$, and not at all in contemporary French. Assuming a null determiner structure for bare-N, this difference implies that null-D are fully licensed in $\mathrm{HC}$, but generally banned in French, leaving for French the structure (1b), in which the bare n-words occupy the determiner position. ${ }^{6,7}$

\section{(4) a. [DP $\mathrm{D}^{0}[\mathrm{NP}$ pesonn ]] Haitian Creole \\ b. [DP Personne $\left[\mathrm{NP}^{0} \mathrm{~N}^{0}\right]$ Contemporary French}

Because they contrast Haitian Creole and European French n-words, these previous works seemingly perpetuate the impression that what is compared are again homogeneous languages that have uniform characteristic properties throughout. However, this is misleading, as these previous studies clearly concentrated on a restricted set of n-words, i.e. the nominal ones and specifically focused on their syntactic properties. Recall, however, that as argued above, the micro-parametric approach defended here predicts that distinct n-words may well have distinct properties so that within language diversity is expected if there are distinct inner structures for negative dependent terms.

It has often been noted in the literature that n-words in French are not all homogeneous in their 'negative' behaviour, and that they do not all participate in negative relations in exactly the same way. For instance, it has been commonly shown that the n-word jamais behaves somewhat differently from personne and rien, which themselves are not entirely parallel either. In particular, for many speakers including myself, jamais can still be found in formal register (mostly written) with a non-negative meaning

6. The analysis of French n-words as determiners is also independently proposed in Sleeman (1996).

7. Zanutini's (1991) original approach differed from other NegP, Neg-Criteron based approaches such as Rizzi's and Hageman's in attempting to correlate the properties of concord to parametric variations in the syntactic position of negation with respect to VP. Although this approach fails to identify a macroparameter between languages allowing negative concord or not, it may well play a renewed role within a micro-parametric approach as one of the factor that can influence the interpretation of negative dependencies. How this factor could be connected to the internal structure of n-words, however, remains to be explored. 
in some characteristic NPI contexts such as, for instance, the rhetorical question in (5) and the contexts in (6):

(5) a. A-t-on jamais vu pareilles choses? ${ }^{8}$

'Has anyone ever seen such things?'

b. [...] mais le ferai-je jamais?

'but will I ever do it?'

(6) a. Je ne crois pas qu'il soit jamais possible [...].

'I don't think it will ever be possible.'

b. [...] dialogue où Socrate se montre plus sophiste que jamais [...]

'a dialogue in which Socrates reveals himself more sophist than ever'

c. Si jamais tu venais [...].

'If you ever came'

Such is not the case for the n-word rien for instance.

8. Note, interestingly, that such rhetorical contexts also permit remnant bare NP (pareilles choses), a fact that we have argued goes along with an NPI interpretation of n-words under the assumption that both sport a remnant null D (Déprez and Martineau 2004). Of further interest is the form of these questions. The examples provided in the text, some of them borrowed from MajBritt Mosegaard Hansen (this volume), and thus drawn from the Frantext data-base in a period from 2000-2007, manifest characteristic stylistic features that clearly flag them as part of a formal high (written) style. These features include: inverted question structure, use of bare nouns, which are notably absent from informal oral registers. It is interesting to note in this regard, that at least in my variety of French, jamais, when used in a non-inverted yes-no question, has a negative meaning. Thus a question like (i) must be answered with $s i$, and cannot be answered with oui, a fact that clearly flags it as negative:

(i) T'as jamais mangé des sushis?

You have never eaten sushis?

Si, mais j'ai pas aimé.

Yes, but I did not like it.

Questions with an inverted structure that contain an n-word cannot be so answered, since they essentially have a rhetorical meaning.

(ii) A-t-on jamais vu chose pareille? \#Si.

Has one ever seen such things? \#Yes. 


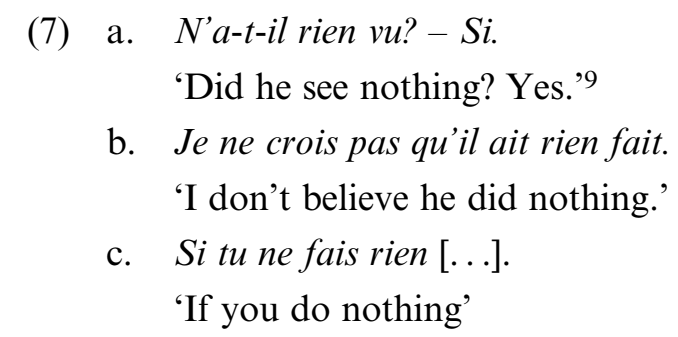

This illustrates the fact that distinct n-words within a given linguistic variety may have distinct properties and as a result, enter in different compositional processes in given contexts. It is entirely possible within our approach that jamais presents a more ambiguous internal structure than other contemporary French n-words. Indeed, the hypothesis made in Déprez $(1999,2000,2004)$ that the change of nominal n-words in French involves the suppression of a null determiner structure does not immediately transpose to the internal structure of adverbial n-words, unless it could be argued following Larson (1985) that adverbs in general, and jamais in particular, have a hidden nominal structure. If so, the disappearance of bare nominals in French, which we argue to be at the root of the change of French n-words, may not directly concern adverbs, and it could well be that, for n-words like jamais, their historical development towards a negative quantifier was only triggered indirectly by some similarity with other n-words like rien and personne and not directly by the disappearance of bare nouns. On this view, note that the possibility that jamais still allows a structure that other n-words have eliminated is not unexpected. Of course, such conjectures, although quite plausible, remain at this point tentative, and only a careful study of the internal structure of adverbs in general and of jamais in particular, could provide support for it. Such a study, however, is quite beyond the scope of the present paper.

Of direct interest to the general thesis of the paper, however, is the fact that n-words in French, whatever the French variety considered, are rarely fully uniform in their properties. To wit, despite many similarities, the very obvious fact that rien generally occurs in a non-argument position, being subject to something akin to the tous-à-gauche construction (Kayne 1977) while personne is not, at least in the contemporary standard language. ${ }^{10}$ This could well reflect a slight difference in internal structure, in

9. Yes in (5a) above imperfectly translates French $s i$, an affirmative answer that can only be used in the context of a negative meaning.

10. In Geneva French, personne is apparently found in the same type of preverbal structure as rien (Ur Shlonsky, personal communication). 
relation with the fact that while personne still has a nominal counterpart in contemporary French, rien no longer does. A possible structural encoding of this difference would preserve for personne the trace/copy of an internal displacement from its original noun position, while there would be none for rien as in (8):

(8) a. [DP personne [... [NP personne $]]$

b. [DP rien]

With this structure, rien is closer to clitic pronouns like le that have often been analyzed internally as intransitive determiners (Postal 1966).

Confronted with this well-known variability in the behaviour of French n-words, Zeijlstra (2008) suggests that this state of affair is symptomatic of languages in which sentential negation is currently evolving. On his view, French is exceptional because its sentential negation is currently undergoing change (cf. the loss of $n e$ ). As noted above, however, such a correlation is not supported by available historical evidence. Moreover, this view makes the prediction that only languages whose negation is currently 'changing' should manifest inner language variability. As demonstrated below, however, such a prediction is not confirmed either. There are clearly languages in which negation appears quite robustly constant while nonetheless manifesting intriguing inner language variation with respect to distinct n-words. Below, such a case is detailed with a careful look at the properties of the equivalent of jamais in Martinique Creole.

As shown in Déprez and Martineau (2004), the behaviour of n-words like pesonn and anyen in Martinique Creole is quite uniform, supporting general description of this language as instantiating strict negative concord of the variable binding type, with $n$-words in a low nominal position as in (2). There are nonetheless some very interesting facts about the n-word jamn that are at odds with too broad a generalization of this picture. As some of our informants have pointed out to us, jamn does not fully behave like the other $\mathrm{n}$-words in their Creole variety ${ }^{11}$. $\mathrm{N}$-words such as as person, anyen, oken moun require the obligatory presence of the sentential negation $p a$ when they occur in declarative contexts, behaving in this regard

11. The data in this section comes from original fieldwork realized in (2001) under our supervision by Timothee Montoute, a native speaker of Martinique Creole with relatives of his. This fieldwork was funded by the European Project Eurocores, granted to Peter Ford Dominey and myself. 
1 like standard NPI expressions. ${ }^{12}$ For jamn in contrast, the co-presence of $2 \quad p a$ appears to be optional:

(9) a. Man (pa) janm dir u bagay kon sa.

'I never told you things like that.'

b. Man janm ale Matinik.

'I never went to Martinique.'

What is of particular interest here is that this optional co-occurrence requirement correlates for jamn with the possibility of giving rise, in certain contexts, to a double negation reading in the co-presence of $p a$.

(10) a. Man pa janm ale Matinik.

'I didn't never go to Martinique. (In fact, I went often.)' 13

b. Je ne suis pas jamais allé à la Martinique.

(En fait, j'y suis allé souvent.)

In other words, in this variety of Martinique Creole jamn seems to fluctuate between an NPI like behaviour, where it combines with sentential $p a$ to produce a single negation reading that is parallel to that of the other $\mathrm{n}$-words of this language, and a negative quantifier behaviour that is closer to the one observed with French $n$-words and produces a double negative reading when combining with sentential negation. To our knowledge, however, there are in MC no comparable known fluctuations in the behaviour of sentential negation. $P a$ is a preverbal head in present day MC, and to our knowledge has always been in the available historical records

12. Haitian Creole manifest so called 'strict negative noncord', which means that n-words are also found in subject position with a co-occuring negation, in contrast to so-called standard, i.e, English-like, NPIs, which cannot occur in subject position. In Déprez (2008), we proposed that n-words licensing in subject position requires the conjunction of two factors: 1) a negative operator that is a head, and 2) DP internal licensing of a null D. If one of these conditions is not met, subject/object asymmetries in NPI licensing are expected. In English, for instance, the sentential negation operator is arguably not a head. In Italian, by contrast, it is DP internal null D licensing that is not possible. Thus for both languages, NPI and n-words display subject/object asymmetries, but this same effect may result from distinct constraints in the two languages.

13. Such a contrastive negative statement requires of course an appropriate context. This is the one provided by our informant: 'You don't even know our foods. I bet you have never ever been to Martinique!' 
1 (see for instance Hazael Massieux 2008). The survey we conducted of 2 available historical texts on the internet ${ }^{14}$ has not revealed any differences.

3 What this illustrates is a characteristic inner variability within an other-

4 wise rather homogeneous language, with a sentential negation form that

5 has remained stable since its known formation. One could argue that this

6 situation illustrates de-creolisation, and that jamn for our informants has

7 been subject to influence from French. This is indeed quite likely, given

8 the situation of diglossia that is typical of Martinique nowadays. Even

9 so, the interesting point here is that such a decreolizing influence seems to

10 have affected only one n-word and not the whole class of these items. Nor

11 does it concern the behaviour of negation, which in the texts surveyed

12 by Pascal Vaillant (2009) does not occur in post-verbal position (Pascal

13 Vaillant, personal communication). Clearly, in this variety the relation 14 of the n-word jamn to negation is distinct from the one exhibited by the explained by distinct properties of sentential negation. More plausible is the suggestion that it is the internal structure of the adverbial jamn that is in part different from that of nominal n-words. Incidentally, it is quite striking that this distinction should concern the equivalent of jamais, which itself, as noted above, shows a greater instability in French too. Put together, these facts clearly suggest that adverbial n-words behave somewhat differently from nominal ones. What the exact structure of adverbial n-word is, and how they differ from nominal ones no doubt deserves further in-depth investigation. But the fact that interesting distinctions appear to group distinct $n$-words by category, i.e. nominal vs. adverbial ones, already provides interesting support to the view defended here that it is the internal syntax of $n$-words that governs the nature of the negative relation they are involved in, rather than the nature of the sentential negation maker.

\subsubsection{Looking inside n-words}

Support for our micro-parametric approach to negative concord requires evidence of robust correlations between the inner syntax of n-words and distinctive properties of the concord relation. But for this to be shown, it is of course necessary to provide first and foremost a detailed analysis of the internal structure of n-words. The goal of this section is to provide

14. The old text consulted have been made publicly available by Hazael-Massieux at http://creoles.free.fr/Cours/ 
1 such an analysis for standard contemporary European French n-words 2 focusing on their feature composition and their modification possibilities. 3 Once the structure is established on solid empirical grounds, the paper 4 then offers an in-depth exploration of the changes that have affected the 5 internal structure of French n-words in the course of their historical devel6 opment. It attempts to chart the detailed diachronic evolution of the 7 internal structure of n-words during their diachronic grammaticalization 8 and discusses the correlations that these changes present with changes 9 in the concord relation they participate in. This section is structured as 10 follows. First, we focus on providing empirical evidence for the complex

15. Our assertion here is based on a rough estimate of occurrences of personne in the Elicop corpus. In each of the files of this corpus that we considered and tallied, the count of negative personne yielded approximately the same result as the count of the positive uses. We examine some distributional evidence, then discuss their feature composition and modification possibilities and finally we take stock of what these data mean for the internal structure of French n-words. In section 3, we turn to historical changes and provide evidence of how French n-words have evolved from a bare nominal type to their contemporary quantificational and determiner type through internal changes in their structure. We examine the time course of feature changes and changes in the modification possibilities.

\subsubsection{Distributional evidence}

At the outset, it is important to recall that the morpheme personne still has a double life in contemporary French. On the one hand, it is a well behaved common count noun meaning 'person', and on the other hand, it is an n-word with an independent strong negative interpretation. A careful comparison of the two words can thus determine minimal factors that enter in their distinction. Given that the frequency of these items is roughly the same, ${ }^{15}$ how do speakers know which is which? A central distinguishing factor is that personne has a (positive) nominal interpretation whenever it co-occurs with a determiner in an argument position (11a). Conversely, its interpretation is generally that of an n-word, whenever it occurs in argument position with no determiner as in (11b). 


\title{
(11) a. J'ai rencontré une/cette/la personne. \\ I-have met a/this/the personne \\ b. J'ai rencontré personne à cette soirée. \\ 'I have met no-one at this event.'
}

\begin{abstract}
The complementary distribution between the presence of overt determiners and the n-word interpretation of personne is quite general, apart from a few interesting cases to which we return below, indicating a competition for the same syntactic position that quite clearly supports placing the n-word personne in a determiner position. Besides accounting for (11), this also provides a straightforward explanation of how a seemingly bare nominal like personne succeeds in meeting the stringent French requirement for obligatory determination. Personne does not need a determiner, whenever it is itself in a determiner position. Worth stressing is furthermore the fact that the presence or absence of a determiner is far more reliable a cue to the interpretation of personne than the co-occurrence of a negative element like ne. As is well known, the presence or absence of ne has no impact whatsoever on the n-word interpretation of a bare personne. Similarly, adding ne to a determined personne as in (10) leaves its nominal interpretation intact:
\end{abstract}

\section{(12) ?? Je n' ai vu une/la personne. \\ I ne saw a person}

Quite clearly then, the presence of a negative operator, even of the strong negator pas, does not influence the interpretation of personne. In fact, a subtle but nonetheless patent semantic distinction remains, even when a negated nomimal de personne in (13a) is compared with an n-word construction like (13b). To get a feel for it, consider the following scenario. Suppose that aliens that look like humans had invaded our world and were hunting the remaining humans they call 'persons' for final annihilation. Now imagine an alien hunter looking for humans in a crowded alien party. If he came up empty handed, he could truthfully utter (13a), but surely not (13b), given the crowd present at the party.

(13) a. Je n'ai pas vu de personne(s) à cette soirée.

'I did not see people.' = (humans)

b. Je n'ai vu personne à cette soirée.

'I did not see anybody at this party.' 
1 Only in (13a) does the lexical meaning remain prevalent, as is expected if 2 personne is indeed a nominal predicate here only. (13a) is of even further 3 interest because of the peculiar [de NP] structure that it features. Kayne 4 (1977) has argued that this construction sports a remnant null determiner, 5 an analysis supported by the fact that, like other attested null D structures, 6 such as Italian bare NPs, [de NP] constructions manifest a characteristic 7 distributional subject/object or pre-verbal/post-verbal asymmetry, as (14) 8 illustrates:

a. *Je ne crois pas que [de personnes étrangères] seront invitées.

I ne think not that of people foreign will be invited

'I don't think foreign people will be invited.'

b. Je ne crois pas qu'il sera invité [de personnes étrangères].

I don't think that there will be invited people foreign

'I don't think there will be foreign people invited.'

The [de NP] structure further manifests a dependency on the presence of an overt c-commanding operator, here negation. This is expected if their remnant null $\mathrm{D}$ is interpreted as a variable that must be appropriately bound for interpretation. In short, distributional asymmetry and necessary operator binding are a hallmark characteristic of remnant null D. Since n-words, by contrast, manifest neither of these characteristics, this is evidence that their structure does not contain a comparable null D.

This much secures the first part of an empirical demonstration that bare n-words do not have the syntax of bare nominals. To yet strengthen the argument, further ${ }^{16}$ empirical evidence is needed that n-words such as personne must be in $\mathrm{D}$. Such evidence can be found, on the one hand, in the interesting exceptions to the complementary distribution mentioned above and, on the other hand, in the modification facts discussed below.

Turning to the exceptions first, (15) shows a surprising instance of bare personne that can only be interpreted as positive:

(15) Vous (?? ne) recevrez un livre par personne.

'You will get one book per person.'

16. Note that the n-word within a DP in (i) can lead to negative concord reading although the presence of $n e$ and, hence, presumably of any negative operator (even null) is in fact banned.

(i) Le *(ne) don de rien à personne est de nos jours presque un égoüsme de rigueur.

The gift of nothing to no one is nowadays quasi-standard egotism 
1 In (15), despite its bareness, personne cannot be coerced into being nega-

tive. Yet as (16) shows, not all PP constructions have this effect on a bare personne:

(16) Je (n') y suis pour personne.

'I am there for no-one.'

So why and how do (15) and (16) differ? Replacing personne by other nominals, we quickly see that, while (17a) displays the properties of a regular PP, taking all sorts of nominal as complements, this is not the case with (17b). In (17b), the range of nominal complements allowed is narrowly restricted, and in effect strictly limited to nominals without determiners:

\section{a. J'y suis pour les/(tous) mes/des amis/, pas pour les/(tous)} mes/des ennemis.

'I am there for the/my/some friends, not for the/my/some enemies.'

b. Vous recevrez un livre par *le/mon/un enfant.

'You will receive one book per the/my/a child.'

(17b) shows that the presence of any overt determiner is simply excluded in these constructions. Yet, as (18) shows, the construction allows adjectival modification, which excludes an analysis of (15) involving $\mathrm{N}$ to $\mathrm{P}$ incorporation or direct $\mathrm{X}^{0}$ selection.

(18) Vous distribuerez un cadeau par gros client fortuné.

'You will distribute one present per big wealthy customer.'

Constructions as in (15) thus appear to strictly select bare singular NP complements ${ }^{17}$, banning any nominal phrase with a more complex determiner structure. This recalls Pereltsvaig's (2008) observation that some Russian prepositions strictly select small nominals with no DP projection.

Returning to n-words, note that if the n-word interpretation of personne were compatible with a bare NP structure, its exclusion from (15) would

17. That the complement of such prepositions must be singular is demonstrated by (i) below, where we see that a phonetically distinct form of plural is unacceptable:

(i) Vous mettrez un ballot d'avoine par cheval/*chevaux. You will put one straw pile by horse-SG/*horse-PL 
1 be mysterious. If, in contrast, it requires a complex D-structure, as defended 2 here, the facts are entirely as predicted, since a complex D-structure fails to 3 meet the selection restriction of this PP construction. (15) further eliminates 4 a putative analysis of bare personne as an N-level pronoun and makes the 5 point that not all apparent bareness can be treated equally, providing clear 6 empirical evidence that the bare n-words of contemporary French must be 7 D-like structures.

$8 \quad$ Let us now briefly see how these observations about personne extend to no longer has a comparable common nominal counterpart in contemporary French, it is nevertheless not hard to find clear evidence that support extending to it the structural conclusions reached above. First, the complementary distribution with determiners is still, to some extent, observable for rien in examples like (19).

\section{(19) Il est très sensible. Un rien le fait sursauter.}

'He is very sensitive. A little thing makes him jump.'

In (19), the nominal meaning of rien (thing) is still perceivable and, as expected, the presence of a determiner is required to allow it. Moreover, although (20) unlike (15) is strictly speaking not fully acceptable, it is nonetheless significantly improved by the addition of a pre-nominal modifier.

a. *Vous utiliserez un sac par rien.

'You will use one bag per little thing.'

b. ?Vous utiliserez un sac par petit rien.

'You will use one bag per little thing.'

(20) illustrates that although the nominal equivalent of rien is no longer in use in contemporary French, it can still be coerced provided that its nominal structure is made obvious by the presence of a pre-nominal adjective, forcing rien, in this case, to be construed in a low nominal position. Note that remarkably, in this case rien loses its negative import. Hence, the reasoning applied to (15) above extends to (20), leading us to conclude that the n-word rien, just like personne, sports a complex determiner structure that makes it unsuitable in (18).

The tests used above do clearly not apply to the French nominal nword aucun, which, quite plainly, must be a D. We return to this n-word below, showing that despite some differences, it nonetheless shares structural similarities with the bare n-words discussed above. 


\subsubsection{The features and modification of n-words}

This section first offers a feature comparison between n-words and their nominal counterparts and then compares the modification possibilities allowed for each type of expression. Turning to features first, we consider gender and number. In (21a), the nomimal personne is feminine and can vary in number, a property here reflected by the determiner, adjectival agreement and co-referring pronouns. The $\mathrm{n}$-word in (21b), in contrast, triggers no adjectival agreement and has corresponding singular and masculine bound pronouns.

(21) a. Les personnes intelligentes pensent qu'elles n'ont pas toujours raison.

'Intelligent persons think they-FEM are not always right.'

b. Personne d'intelligent (ne) pense qu'il a toujours raison.

'No one intelligent thinks he is always right.'

In this respect, n-words behave like the existential quantifier quelqu'un (someone), also unmarked for gender and number. Interestingly, despite number invariability, n-words seem semantically plural, as shown by (22), where personne occurs with a verb that requires a plural subject.

(22) Personne ne se rassemble plus ici.

'No-one gathers here anymore.'

In what respect do these facts support the view that n-words occupy a high D-like position in their functional structure? Note first that the lack of gender and number features make n-words characteristically un-nominal. Moreover, syntactic invariability and/or semantic plurality appears to be characteristic of a certain type of D-elements in French such as the existential quantifier quelqu'un or the bare quantificational pronouns or question words qui and quoi. These similarities support the view that $\mathrm{n}$ words share feature properties with pronouns and quantifiers, but not with nouns, hence providing evidence that they are merged in a D position. ${ }^{18}$ Further support arises from their modification properties. (23)

18. The view that $n$-words are pronouns has long been recognized in the classic literature (Gougeheim 1951, Grevisse 1980). The claim that n-words are in $\mathrm{D}$, adds a hierarchical dimension to this claim that has consequences on adjectival modification. 
1 shows that pre-nominal adjectives are excluded with n-words, while they 2 are possible and stackable with their nominal counterparts.

(23) a. *J'ai rencontré autre charmante petite personne.

'I have met other charming small nobody.'

b. J'ai rencontré une autre charmante petite personne.

'I have met an other small charming small person.'

In the spirit of Cinque's (1994) hierarchical approach to modification, the lack of pre-nominal modification is a further indication that these n-words must occupy a position at least higher than NP in the DP structure. But it is not just pre-nominal modification that is excluded with n-words. More generally, n-words like personne and rien do not allow direct adjectival modification; they require a specific modification construction with de as in (24), which I henceforth term 'indirect de-modification'. As (24) shows, this again is a property that n-words share with existential quantifiers like quelqu'un and bare question words like qui or quoi. ${ }^{19}$

(24) *Personne/rien/quelqu'un/qui/quoi *(d)'intéressant

'No one/nothing/someone/who/what (of) interesting'

Kayne (1994) observes that indirect de modification is more constrained than regular modification, in that it disallows stacking, as in (25):

*J'ai rencontré personne/quelqu'un/qui de charmant de petit.

'I have met no one/someone/who/of charming of small.'

He argues that this anti-stacking constraint speaks against assigning these constructions a traditional adjunction structure and following Huot (1981), proposes a structure akin to relative clause modification with de as a complementizer-like element as in (26):

(26) $\left[\mathrm{D}^{0}\left[\mathrm{DP} / \mathrm{PP}\right.\right.$ quelqu'un/personne $\left[\right.$ de $\left[\mathrm{IP}\right.$ intelligent $\left.\left.\left.\mathrm{I}^{0} \mathbf{t}\right]\right]\right]$

(Kayne 1994)

In (26), the n-word or quantifier raises from a position internal to the clause to Spec $d e$, in a fashion paralleling that of predicate inversion in DP (den Dikken 1998). Kayne, following (Huot 1981), notes one intrigu-

19. As Déprez (2000) notes, indirect modification of this type is not possible with universal quantifiers, a fact that strongly suggests that n-words are like existential/indefinite quantifiers or numerals in their syntactic nature, i.e. quantificational indefinites. 


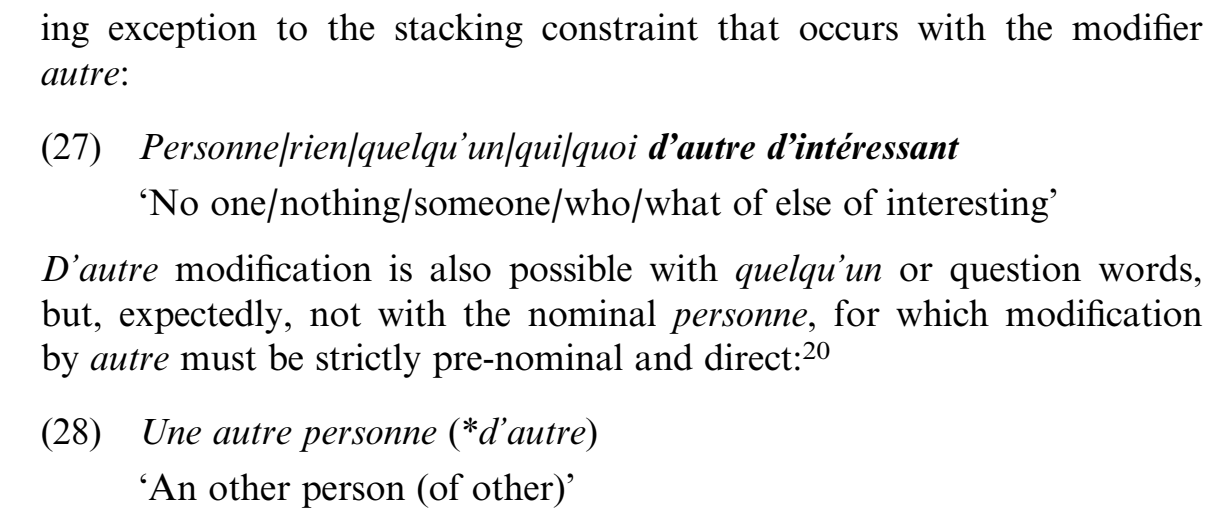

\section{(27) Personne/rien/quelqu'un/qui/quoi d'autre d'intéressant}

'No one/nothing/someone/who/what of else of interesting'

D'autre modification is also possible with quelqu'un or question words, but, expectedly, not with the nominal personne, for which modification by autre must be strictly pre-nominal and direct: ${ }^{20}$

(28) Une autre personne (*d'autre)

'An other person (of other)'

The modifier autre is peculiar in other respects that are of interest here. First, like a few other pre-nominal adjectives in French (divers, différent), autre can sometimes play the role of a determiner and/or a pronoun.

(29) Autres temps, autres moeurs, autre histoire!

'Other times, other mores, other stories!'

Clearly as well, it must always be the highest pre-nominal modifier in any noun phrase, as it can never be preceded by any other pre-nominal adjective, like for instance petit.

(30) *Une petite autre voiture/une autre petite voiture

'A small other car/another small car'

In these respects, autre differs from regular adjectives, appearing instead to share properties with numerals. In fact, like numerals, it can modify pronouns.

(31) nous trois, nous autres

'we three, we others'

Interestingly, however, autre can also modify numerals, as in (32a), but the stacking of pronouns and numerals is not allowed (cf. 32b):
a. trois autres
'three others'
b. *nous trois autre
'*we three others'

20. Post-nominal autre is also marginally possible, but with a meaning closer to that of different: une personne autre. 
1 Furthermore, while indirect de modification is sometimes possible with 2 regular adjectives where the noun phrase is contrastively focused as in 3 (33), indirect modification with d'autre is always excluded. With nouns, 4 autre must always remain pre-nominal with direct modification.

(33) J'ai trois voitures de bleues/*d'autres, pas quatre.

'I have three car of blue/of other, not four.'21

In sum, indirect modification with d'autre is only possible with n-words, 9 existential quantifiers and question words, never with other nominal ex10 pressions. This clearly gives it a peculiar status, shared with no other autre involves quantity, not noun modification, and proposed the structure in (34):

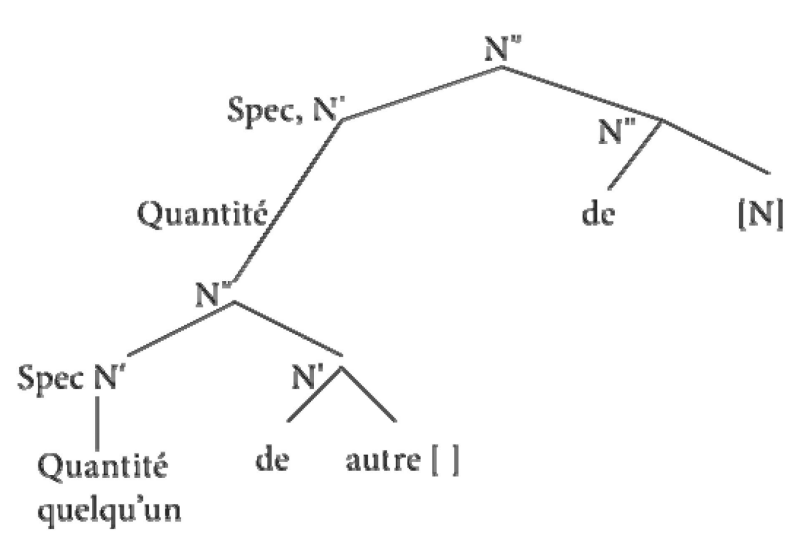

Huot's suggestion in effect groups modification by d'autre with other degree modifiers like de plus (more), or de moins (less) (quelqu'un/quoi de plus/de moins 'someone/what more/less'). In a current model, a possible

21. Indirect $d e$-modification is also possible with so-called 'quantitative en-pronominalization'. As (ia) shows, for regular adjectives, both direct and de modification are possible. Here again, however, modification with d'autre is excluded:

(i) a. J'en ai TROIS (de) petites, pas quatre.

I of them have three of small, not four

b. J'en ai trois $\left({ }^{*} d^{\prime}\right)$ autres.

I of them have three of other, not four 
interpretation of this insight would assume that d'autre involves $\mathrm{NumP}^{22}$ and not NP modification. To account for the above modification possibilities as well as for its similarity with numerals, we propose that autre can occupy the head of NumP, so that it can be preceded by elements that occupy either the Spec of NumP or the head of D. We have seen Kayne's (1994) proposal for indirect de modification with regular adjectives. Adapting Huot's suggestion, we propose to account for the stacking effect by assuming that autre can be a NumP head modifier that can move along with the head out of the clausal constituent of the indirect adjectival demodification and be stranded in Spec DP, while the n-word moves even higher in the DP structure as in (35a), in a fashion akin to CP recursion.

(35) a. [FP personne ${ }_{\mathrm{i}}\left[\mathrm{DP} / \mathrm{PP} d e\left[\mathrm{t}_{\mathrm{i}} \text { autre } \mathrm{t}_{\mathrm{i}}\right]_{\mathrm{k}}\left[\boldsymbol{d e}\right.\right.$ [IP sympatique Infl $\left.\left.\left.\mathrm{t}_{\mathrm{k}}\right]\right]\right]$ noone of other of friendly 'no one else friendly'

b. $\left[\text { Qui }_{i}\left[\mathrm{t}_{\mathrm{i}} \text { d'autre }\right]\right]_{\mathrm{k}}$ as tu invité [de sympatique $\left.t_{k}\right]$ ? who of other has you invited of friendly 'Who else friendly have you invited?'

c. [ Qui $_{i}$ as tu invité [[ $\mathrm{t}_{\mathrm{i}}$ d'autre] [de sympatique $\left.\left.\mathrm{t}_{\mathrm{i}}\right]\right]$ who has you invited of other of friendly 'Who else have you invided that is friendly?'

d. Je n'ai rien ${ }_{i} \quad v u\left[\left[\mathrm{t}_{\mathrm{i}}\right.\right.$ d'autre] [d'intéressant $\left.\left.\mathrm{t}_{\mathrm{i}}\right]\right]$ I $n e$-have nothing seen of-other of-interesting 'I have seen nothing else interesting.'

That d'autre can indeed move along with a quantity expression is confirmed by (35b), where d'autre has moved along with a wh-term to SpecCP. That movement out of the projection containing the modifier is also possible is further confirmed by (35c), where d'autre appears optionally stranded by the moved wh-term. (35d) replicates this structure with the moved n-word rien. ${ }^{23}$ (35a) accounts, on the one hand, for the exceptional stacking possibility with d'autre and on the other hand, for the

22. Throughout, we assume NumP to be the projection that hosts numerals and weak quantifiers, not number. Number in our view is a separate PIP projection as in Zamparelli's more recent work.

23. Curiously and interestingly, stranding in this case is obligatory. I do not at this point have an explanation for this fact. 
1 restricted nature of the elements that allow it. Only elements moving out 2 of NumP to a higher position in DP, here termed 'FP', manifest this DP 3 recursion possibility.

To sum up, we have shown that the modification properties of n-words are very different from those of regular nouns. The facts reviewed above provide evidence for the quantificational nature of n-words and for the proposal that they occupy a high position within DP. We have spent some time detailing the peculiar facts of d'autre modification here because, as discussed below, there are revealing changes in this respect in the evolution of the internal structure of $n$-words.

\subsubsection{Mapping the structure}

The above discussion has provided some empirical evidence for the complex internal structure of n-words, but has so far remained theoretically imprecise with respect to the detailed mapping of their internal structure. This section presents an effort to flesh out this internal structure in more details. For a start, we adopt Zamparelli's (1995) proposal to subdivide the DP structure in three hierarchical quantificational zones that he termed 'SDP', 'PDP', and 'KIP'. For Zamparelli, only weak quantifiers that are housed in PDP are compatible with ne cliticization in Italian, because only these are close enough to license the trace of ne. As Zamparelli notes, the Italian quantifier qualcuno is ambiguous in this respect. When compatible with ne cliticisation, qualcuno simply is an equivalent of some. When incompatible with it, qualcuno is restricted to human reference and is a pronominal meaning 'someone'. To account for this ambiguity, Zamparelli proposes that qualcuno is merged as a weak quantifier in $\mathrm{PDP} / \mathrm{NumP}$ and has the possibility to move or remerge higher as a strong quantifier in SDP/DP.

Adapting this approach to French, we note that the ambiguity observed for qualcuno is replicated by quelqu'un vs quelques uns. Like qualcuno, which meanins 'someone', singular quelqu'un fails to allow partitive/quantitative en clitization and has the same meaning (cf. 36). Quelques uns, by contrast, has the meaning of 'some' and is compatible with partitive and with en cliticization and inflected for number.

(36) J'en ai rencontré quelques uns/*quelqu'un/ *quelqu'une de mes amis. 'I have met some-PL/someone/some of my friends.'

I thus suggest that, similarly to qualcuno $+n e$, quelques uns is merged in $\mathrm{PDP} / \mathrm{NumP}$, while quelqu'un is either directly merged or obligatorily moved 
1 to SDP/DP. Since, as seen above, the n-words personne and rien behave in 2 many respects like the existential quantifier quelqu'un, we now have analog3 ical evidence to posit the same structure for these contemporary n-words.

4 Note that, as expected on this proposal, n-words are essentially incom5 patible with true partitivity and with quantitative en cliticization (37):

a. ?? Je ne connais personne de tes amis.

'I know no one of your friends.'

b. *Je n'en connais personne. ${ }^{24}$

'I know no one of them.'

Assuming that the similarities warrant a parallel treatment, I propose the following structure for the French n-words:

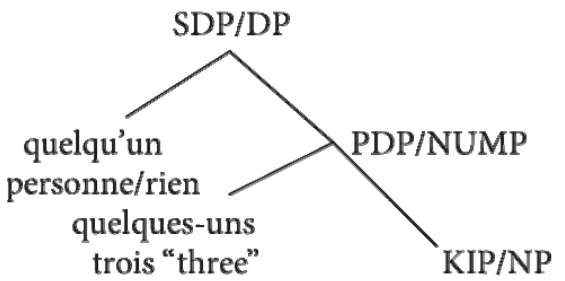

(38) accounts for all the properties of the n-words detailed above, as it assigns them to the highest position in DP and implies that they behave essentially as strong existential quantifiers. On this view, their invariability is expected, given that they are merged above the DP layer where number agreement is syntactically negotiated, as are their modification possibilities, given that they behave essentially as quantity expressions. ${ }^{25}$ For indirect de-modification, we have adopted Kayne's (1994) structure to which we have added a layer to allow modification by d'autre as in (33a) above. On this view, d'autre modification and the lack of partitive structure can be taken as evidence of the additional movement step towards the highest layer of SDP/DP.

24. One should not confuse true partitive constructions, which take a full DP as a complement, with pseudo-partitive ones. The latter is permitted and commonly derives apparent quantitative en contructions with rien (cf. De ça, il n'en reste rien/peu de chose 'of that there is nothing/little left' vs. ?*De tes jouets, je n'en casse rien.' of your toys, I broke none').

25. Recall that as posited in section 2.1 , rien differs from personne in being directly merged in this high position and leaving no trace of any displacement. 
To be complete, our study of the structure of contemporary French nominal n-expressions requires that one more expression, namely aucun $N$, be considered. As this expression and its historical evolution is discussed in great details in Déprez and Martineau (2004), our discussion here will remain brief. In contrast to personne and rien, aucun $N$ clearly contains both a determiner element and an obligatory N, so that the status of aucun as a determiner is not in doubt. Unlike personne and rien, however, this nominal n-word expression allows both quantitative en cliticization, and true partitive structures.

(39) Je n'ai vu aucun de tes enfants. Je n'en ai vu aucun.

'I have not seen any of your children. I have seen none of them.'

In this respect, aucun seems to behave both like a numeral in French and like the strong quantifier chacun, which can vary in gender, but notably not in number.

(40) a. Aucune idée n'a été acceptée.

'No idea was accepted.'

b. *Aucunes idées n'ont été acceptée(s).

'No ideas were accepted.'

To account for these differences as well as for the similarities between aucun and the other nominal French n-words, I propose that the determiner part aucun is merged in PDP and moves to SDP as in (39), while the nominal part continues to behave like a regular NP.

(41)

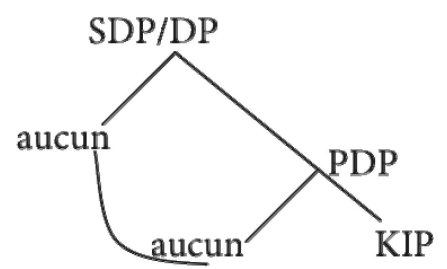

Thus, like numerals, aucun participates in a strong/weak alternation, but unlike numerals, it does not allow a preceding determiner in contemporary French (les trois, vs *les aucuns). This movement to the higher layer of the DP is obligatory for this n-expression, as in the case of rien/ personne. As Martineau \& Déprez (2004) have shown, this was not always true in the history of French. Expressions like *Les aucuns amis 'the some friends' are commonly found up to the sixteenth century. This, and the fact that aucun is invariable in number, motivates an analysis in which this $\mathrm{n}$-determiner is merged in the highest $\mathrm{D}$ position. 
To sum up, on the basis of their distributional, feature and modification properties, I have argued in this section that all nominal French n-words occupy the highest quantificational position in the DP and, as such, behave syntactically like determiners and strong quantifiers. With respect to some of their other properties, these n-words seem to partake both in the behaviour of strong and of weak quantifiers. To account for this, I proposed that they be merged in PDP, a position equated elsewhere with NumP, and move to SDP, a position equated elsewhere with DP. Of particular interest moreover is the fact that this high position correlates with the loss of number KIP variation. All the nominal French n-words are invariable in gender and number, and consequently always trigger singular or more exactly unmarked agreement.

As will be seen in section 3 , the loss of feature variability historically correlates with the loss of nominal status and the development of a pronominal and quantificational status. What we observe for all French nominal n-words is the loss of variability and the rise up the DP structure to the highest position, correlating with a gain in pronominal and quantificational strength. It is these combined properties that account, in our view, for their possibility to ambiguously partake in the complex polyadic resumptive quantification that produces the negative concord readings as well as in the scopal quantification that produce double negative readings as discussed in Déprez (2000), following May (1989).

\section{The internal evolution of French n-words}

Having discussed in detail the syntactic nature and structure of contemporary French n-words, it is now time to turn to their historical evolution, in order to chart the course of their internal change as well as to identify the micro-parametric nature of this evolution. We offer here a detailed examination of the evolution of rien and personne focusing on two central aspects, changes in their featural make up and changes in their modification possibilities. Our study is based on searches in the electronic databases Frantext and TFA.

\subsection{Changing Features}

Let us first consider feature changes. Both personne and rien started out as feminine and count nouns, and both ended up on their n-word interpretation as singular and masculine nominal expressions or, more exactly, as expressions unmarked for both number and gender. Charting the course of changes of this nature in historical corpora, however, is a difficult under- 
1 taking, as in French, cues to determine the gender and number make up of 2 nominal expressions are accessible only indirectly, i.e. through inspection 3 of their dependent satellites.

$4 \quad$ In Old and Middle French, rien, which derives from the Latin noun res 5 (thing), was a feminine noun that could refer to inanimate or animate entities. (42) provides an example from Chretien de Troyes thirteenth century of an animate nominal rien preceded by a feminine definite determiner.

(42) Quant la rien voit que il plus ainme [...] when the thing sees that he most loves

'When he sees the person he most loves' (Chrétien, de Troyes, 1240, Le Chevalier de la Charrette (Lancelot)) Examples with a clearly feminine determiner as la rien can be found up to the Middle of the sixteenth century in the (the prose text) Cent Nouvelles Nouvelles (cf. 43):

(43) [...] qu'elle voit d'elle éloigner la rien en ce monde dont la presence plus luy plait [...].

'that she sees leaving her the thing in this world of which she most like the presence'

(Monseigneur de La Roche, 1550, Les Cent Nouvelles Nouvelles)

This appears to be the last example of this sort found in Frantext, which suggests that rien became unmarked for gender around the middle of the sixteenth century. Indeed, confirming this, it is around this time that the first examples of rien with clear instances of masculine determiners are found, as attested in (44), an example from the poet Ronsard dated from 1552:

(44) [...] elle auroit cognoissance Qu'un rien qu'on ne voit pas, fait souvent un grand [...].

'She would have knowledge that a thing that one cannot see often makes a large $[\ldots]$ '

(Pierre de Ronsard, 1524-1585, Les Amours)

That rien becomes invariable for gender does not however mean that it completely loses its nominal character. Indeed, rien could still be found with a (masculine) determiner and a positive meaning up to almost the end of the classical period, as attested by the following 1896 examples from the famous Goncourt Brothers. Interestingly, rien is now strictly inanimate in reference: 


\section{(45) [...] pour moi, le rien qui m'arrive d'heureux, c'est toujours [...].}

'For me, the thing that happens to me that is happy is always [...].'

(Edmond and Jules de Goncourt, 1822-1896, Journal)

Thus, the loss of gender and animacy reference represents the first step in the grammaticalization of this expression. Turning to number, we face the same difficulty in determining when exactly rien stopped allowing number inflection, as it can vary even nowadays, when it is a noun clearly accompanied by a determiner (cf. des riens). To get some idea we searched our databases for examples of rien overtly marked for number without a determiner. The last example where riens occurs as a clear bare argument occurs in 1559 in Frantext.

(46) Le Roy ne luy respondit riens, sinon: "m'asseurez-vous que vous l'avez [...].

'The king did not answers things, except: "confort me that you have it'

(Marguerite de Navarre, 1559, L’Heptaméron)

Based on this indirect evidence, we tentatively suggest that it is around the end of the sixteenth century that bare rien effectively ceases to be variable in number. But again, rien does not immediately cease to have a nominal character, since it can be found as an invariable bare nominal expression without determiner, with a positive meaning in downward entailing contexts up to the classical period:

(47) Diable m'emporte si j'entends rien en médecine. devil takes-me if I-understand anything in medicine 'The hell if I understand anything about medicine.'

(Molière, 1673, Le malade imaginaire)

The continuing nominal character of rien is confirmed by evidence based on modification possibilities, to which we turn in Section 3.2. Before, however, let us first detail the time course of feature change for the n-word personne. Turning to personne, the exact time course of the loss of its features is even more difficult to determine from corpus searches, given the continuous current use of its nominal counterpart. We have nonetheless endeavoured to chart an approximate course by looking at examples of bare personne triggering feminine agreement with an adjective, a past participle or a co-referring pronoun. In Old French bare personne was clearly feminine, as witnessed by (48) from the Vie de St Alexis (eleventh century) with a co-referring feminine pronoun. 
(48) Car la sainte Ecriture si nous dit et tesmoigne, because the Saint Writing here us tells and witnesses, Qu'au monde n'a personne, pour tant qu' that-in-the world there-isn't (a) person for as-much-as elle se joigne.

she REFL joins

'Because the Holy Bible tells us here that in the world that there is no one that would be found.'

(Sarre Nguissaly 121: 2003)

The capacity to trigger feminine agreement for bare personne seems to have lasted up to the seventeenth century, as witnessed by (49) with a past participle agreement from L'Astrée (1607-1625):

\section{Je ne puis dire avec vérité que jamais personne}

I ne can tell with truthfulness that ever person-FEM

ne fut plys aymée que moi.

ne was more loved-FEM than me

'I cannot tell in truth that anyone was ever loved more than me.'

(H. Durfé, 1607-1625, Astrée, 536, in Nguissaly 126, 2003)

Yet, as early as the mid fourteenth century, there are also examples without agreement:

(50) Jamais nouvelle n'en seroit a personne vivant.

Never news ne it-GEN be-COND-3PSG to person alive

'Never will this be news to any person alive.'

(Monseigneur de La Roche, 1550, Cent Nouvelles Nouvelles, 387, 73)

More generally, it would seem that after the Renaissance, bare personne had definitely lost its capacity to be marked for gender. It thus came to generally trigger default masculine agreement and co-reference, as is shown in (51) from Pascal 1670, where both pronominal reference and past participle agreement show masculine and singular agreement:

(51) Personne n'a d'assurance - hors la foi, s'il veille ou s'il dort.

'Not anyone has assurance - outside faith, of whether he is awake or asleep.'

(Pascal, 1670, Pensées, 164, in Nguissaly 2003: pages 132) 
1 To sum up, evidence from our corpus searches reveals that both rien and 2 personne seem to have lost their characteristic nominal features of, first, 3 gender (by the middle of the sixteenth century) and, second, number (at 4 the end of that century).

\subsection{Changing Modification}

This section focuses on historical changes in modification possibilities. I will argue that even more than feature loss, the changes in modification provide a striking window into the evolving internal structure of n-words. Going back to its earlier occurrences, rien was modifiable by a number of pre-nominal adjectival quantifiers, like nulle and toute, all of which attest to its feminine gender. In Frantext, the last example of nulle riens 'no things' is found in the fifteenth century in Christine de Pisan's work:

(52) Ne deüst faire nulle riens, Toute fois entr'eulx une riens [.. . ]

'I had to do no thing, yet between then one thing [...]'

(Christine de Pisan, 1402, Le Livre du chemin de lonc estude)

There are 94 further occurrences of toute rien 'all things' in the TFA database. Our searches in this database revealed that this feminine modification was possible up to 1381. In Frantext, the last example of this modification is found in 1550, again in the Cent Nouvelles Nouvelles.

(53) [. . . et sur toute rien luy estoit [.. .] defendu le mestier [...].

'and on everything it was forbidden to him to take up the profession'

(Monseigneur de La Roche, 1550, Les Cent Nouvelles Nouvelles)

It is of course difficult to identify regular modifiers in a corpus, which is why we chose to focus in our searches on modification by autre, which turns out to be particularly revealing in its evolution. In some early examples, we see that autre began as a prenominal modifier of rien as in (52). This is comparable to today's modification of regular nouns.

Nous ne demandons autre riens Que nous y mettre.

'We are not asking for other things than to put ourselves to it.'

(Anonymous, 1376, Miracle de sainte Bautheuch)

The last example of this kind given here in (53) occurs in 1606. Rien in (55) is clearly masculine, and also plausibly invariable in gender, but still positive and here preceded by a determiner. 
(55) Dieu qui de rien fit tout, et qui de tout encore peut faire un autre rien, [...]

'God who out of nothing made everything and who of everything can yet make another thing.'

\section{(J. Bertaut, 1606, Recueil Qq. Vers Amoureux)}

Taking the pre-nominal position of autre to be indicative of the nature of rien, examples like (54) and (55) suggest that its nominal character, as indicated by its positioning in the $\mathrm{N}$ projection, lasted somewhat beyond the loss of its gender and number features, up to the beginning of the seventeenth century. Yet, the fact that no example of this sort occurred after this date can be taken to mark the end of a historical phase. From 1606 on, throughout the classical period and up to the early twentieth century, our data indicate that autre has become a post-nominal modifier of rien as in (56).

[...] elle me dit adieu, et se retira sans me donner rien autre chose qu'une bague $[. .$.$] .$

'She said goodbye and left without giving me anything other than a ring.' (A.-R. Lesage, 1732, Histoire de Gil Blas de Sant)

Despite the change of position, modification by autre remains direct at this time, i.e. with no linking $d e$. In its shape then, this modification remains seemingly close to regular post-nominal adjectival structures. However, recall that as seen above, modification by autre of regular nouns is strictly pre-nominal up to contemporary French. Thus, in effect, post-nominal direct modification by autre can be taken to indicate that rien no longer behaves like a regular noun in the language. Taking the position of autre to mark the upper limit of NP internal modification, as is suggested by its high contemporary position, examples like (56) imply that by the seventeenth century, rien had definitely left the nominal domain for the NumP domain. That is, after a period of transition where autre could occur alternatively as pre or post-nominal modifier, i.e. where on our view, movement of rien from the nominal domain to the NumP domain remained optional, rien came to be directly merged in NumP, accounting for obligatory post-nominal autre. This form of direct post-nominal modification in turn is maintained through the classical period and is found rather late, i.e. up to 1925, in the writings of Claudel. Of interest is the fact that in Claudel's writings, as well as throughout the classical period, characteristic NPI uses of n-words in downward entailing contexts are commonly found. As shown by the following table reproduced from Déprez and 


\section{Martineau (2004), positive uses and polarity context uses (excluding nega- tion) of n-words amounted to about 30\% during the seventeenth and $20 \%$ during the eighteenth century. \\ Table 1. Frequency of aucun in positive, polarity and negative contexts

\begin{tabular}{|l|c|c|c|}
\hline periods & positive contexts & polarity contexts & negative contexts \\
\hline 17 th century & $3.5 \%(7 / 200)$ & $27.5 \%$ & $69 \%$ \\
\hline 19 th century & $0 \%$ & $20.5 \%$ & $79 \%$ \\
\hline
\end{tabular}

Against the background of this diachronic study, we can see that direct post-nominal modification with autre appears to be a characteristic feature of the classical period (seventeenth-eighteenth century), which coincides with the increasing use of n-words as NPIs (Déprez and Martineau).

As evidenced in Martineau \& Déprez (2004), Quebec French also contrasts with contemporary continental French in commonly allowing the co-occurrence of the negation pas with n-words as well as common NPI uses of these expressions. In short, there are both diachronic and comparative evidence of the correlated occurrence of direct post-nominal modification by autre and of the use of n-words as polarity items. ${ }^{26}$

The next pattern of autre modification observed in our diachronic corpus is that of indirect modification with de. Notably, this indirect modification appears to have a peculiar historical evolution. In Frantext, it is first found in the twelfth century in the works of Chretien de Troyes, but it occurs only sporadically. After this, rather curiously and quite interestingly, this pattern disappears entirely from the corpus until 1843, where we see it re-surface, after a seven century gap, in the writings of Honoré de Balzac.

(57) [...] là, madame; ne vous faut-il rien d'autre?

'There madam; do you need nothing else?'

(H. de Balzac, 1843, La Rabouilleuse)

The use of this indirect pattern with autre remains fairly infrequent until about 1890, where it finally reaches about equal status with the previously discussed post-nominal direct modification rien autre and rien autre chose. Yet it is not until 1909, in the writings of André Gide, that the indirect de-modification pattern firmly dominates and definitely wins over

26. For a more detailed discussion of the NPI uses of n-words both in classical French and in Quebec French, see Déprez and Martineau (2004). 
1 the direct modification pattern. Worth stressing here is the fact that this is 2 an interesting discovery, as our research shows, apparently for the first 3 time, that the use of the modern indirect modification pattern with de 4 as in rien d'autre was not firmly established until essentially the beginning 5 of the twentieth century. Referring back to the findings of Déprez and 6 Martineau (2004) again, this appears to coincide with the rise of the strongly negative interpretation of n-words. 


\subsection{Theoretical implications and conclusions}

The previous section has provided detailed evidence for the evolution of the $\mathrm{n}$-expressions rien and personne, attempting to establish, first, the time course of their feature loss, and second, correlated structural changes. It is now time to take stock of these observations and to consider their theoretical consequences.

Summarizing and highlighting the central facts, we have observed three stages in the syntactic evolution of $n$-expressions. In the first stage, $\mathrm{n}$-words are essentially nominal in nature, as evidenced by the use of determiners, their gender and number features as well as by the pre-nominal position of the modifier autre. By and large, we have dated the loss of features to the middle of the sixteenth century and the disappearance of the pre-nominal modification pattern by the beginning of the seventeenth century. We concluded that, structurally, during this period the n-expressions occurred within the NP layer of their nominal structure. In the second stage, the n-words lost their nominal features and became invariable with respect to both number and gender. Modification by autre is now postnominal but it remains direct, without $d e$. We have suggested that at this stage, which essentially spans the classical period, these n-words climbed a first step within the nominal structure, reaching NumP so that they are now directly merged in this position, accounting for the strictly postnominal position of autre. The third stage corresponds in our data with the appearance of indirect de modification. As discussed in Section 2.3., this type of modification with d'autre corresponds to quantity or degree modification, like modification with de plus, or de moins, and indicates that n-words have now taken on a quantificational nature. Following Zamparelli (1995), we have assumed that this could correspond syntactically to yet another step up the structural ladder of the DP structure, reaching in Zamparelli's terms, the level of strong quantification or SDP. Putting all these assumptions together, the following structure sums up the evolution of the n-word that our evidence has unearthed.

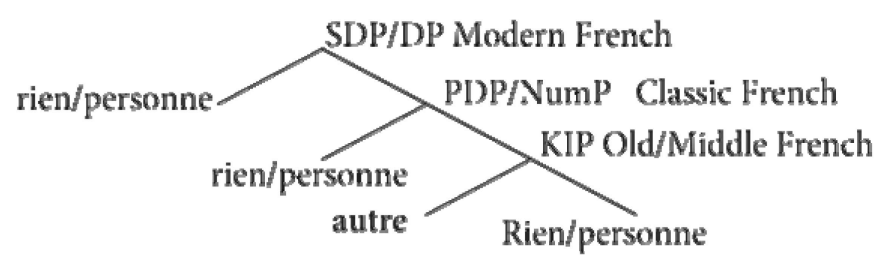

On this view, the evolution of $\mathrm{n}$-words corresponds to a gradual three-step movement up the DP-structure. Of particular interest are the parallels that 
1 can be observed between the historical course of this evolution and the 2 findings that Déprez and Martineau (2004) and Martineau \& Déprez 3 (2004) report on the historical evolution of the meaning of n-words. 4 Focusing on the interpretation of aucun, they have distinguished three 5 periods that largely correspond to the ones we have distinguished here. In 6 the first period, corresponding to Old and Middle French, the interpreta7 tion of n-words seems largely context independent and positive. Beginning 8 with the sixteenth century and into the classical period, however, the inter9 pretation of $\mathrm{n}$-words becomes context dependent. As Martineau \& Déprez 10 (2004) argue, n-words at this period manifest characteristic features of 1 NPI: They are licensed only in restricted contexts, i.e. the so-called 'affective' contexts, which in addition to downward entailing contexts include interrogatives and comparatives; they can be licensed at long distance; they are not licensed in subject position and are compatible with negation, including the negation pas, which is dominant at the time at the sole exponent of sentential negative meaning. Finally, in the last period, which corresponds to the birth of Modern French at the beginning of the twentieth century, n-words come to take on a negative meaning of their own, now occurring alone, i.e. without the co-presence of the sentential negative marker pas. This evolution is well known. What had not been put together up to now is the parallelism that the meaning evolution of n-words shows with the changes that affect their internal structure. This is what this section hopes to have accomplished by coupling the historical evolution of the meaning contribution of $n$-words at the sentential level, with a careful study of their internal change.

To finalize the correlation of the two, we propose that n-words undergo the following evolution. In the first period of their evolution, their structure contains a null determiner that is essentially equivalent to the one posited for existentially or generically interpreted bare noun phrases. That is, for all intent and purposes, rien and personne function like bare indefinite noun phrases. At the beginning of this period, personne and rien are still nominal and count nouns, and their null determiner is essentially the same as that of other indefinite noun phrases in the language. Following Eckardt's (2006) very interesting analysis of the semantic evolution of French negative elements within a focus alternative semantics model à la Rooth (1985), we take this to be a period in which, when used in negative contexts, these expressions came to be used in emphatic denial first, simply under contingent circumstances, that is, only when their contexts license plausible alternatives to their very general predicative meaning of 'person' or 'thing'. Such contexts were essentially comparable to 
what is needed in current modern French to license the denial of a regular indefinite noun phrase like une personne. That is, they are for instance comparable to the alien context we set up in (11) above to make sense of the denial of the determined expression de personne. This context is set up to contingently oppose personne to 'aliens', thus introducing a plausible alternative that is disjoint from the meaning of 'person', as required under Rooth alternative-focus semantics. Other relevant plausible contexts could set up relevant alternatives by opposing 'persons' to objects, plants, animals or more generally, to 'non-person' entities, following Eckardt (2006).

Gradually, however, as the n-words lose their ability to be marked for gender and number, their nominal quality is altered. At the same time, regular indefinite null determiners start to become increasingly rare in assertive contexts, due to the general decline (phonetic erosion) of plural marking on nouns, and the consequent growing reliance on overt determiners marking for number distinctions. We would like to propose that the conjunction of these syntactic changes is what sets up the stage to alter the structure of n-words and the type of alternative they evoke for a noncontingent use of personne in emphatic negative constructions. In other words, it is at this time, following Eckardt (2006), that n-words become focused existentially quantified predicates which call for other predicates as their alternatives. Eckardt (2006: 256) formalizes this change as follows:

(62) [[ personne ]] $=\lambda \mathrm{Q} \exists x(\operatorname{PERSON}(x) \wedge \mathrm{Q}(x))$ 'some person' $\operatorname{Alt}($ personne $)=\{\lambda \mathrm{Q} \exists x(\operatorname{BAKER}(x) \wedge \mathrm{Q}(x)), \lambda \mathrm{Q} \exists x(\operatorname{PRIEST}(x) \wedge$ $\mathrm{Q}(x)), \lambda \mathrm{Q} \exists x(\operatorname{BUTCHER}(x) \wedge \mathrm{Q}(x)), \ldots\}$

Pragmatic function: Must be used in emphatic focus.

In (62), the alternatives to personne are no longer non-persons, but rather subtypes of persons, such as bakers, priests, scholar, students, i.e. alternatives to predicates describing human types. A consequence of this change is that alternative propositions constituting the 'focus semantic value' (Rooth 1985) of these expressions are now in a logical entailment relation with the stated proposition that contains them. (Being a baker, butcher, or scholar entails being a person.) As a result, the stated proposition can meet the pragmatic requirement of being the most striking one among the space of alternatives, only under special conditions, i.e. only under negation or when occurring in downward entailing contexts (see Eckardt 2006 for precisions). During this period of gradual change, culminating in the second period of their evolution, the one starting with the end of the sixteenth century and spanning the classical period, we propose that the n-word gradually moved up their DP, to Zamparelli's PDP part of 
1 the structure. In this step in their evolution, n-words are semantically NPIs and we have seen above that modification with autre then regularly occurs in a post-position. Now according to Eckardt (2006) again, NPIs are characterized by a lexical requirement for focus, which enforces their use in restricted environments. Eckardt, however, does not specify how this lexical requirement comes about. Given the evidence we provide of internal change at this level, we would like to suggest that the requirement for focus on rien and personne is not really lexical, as Eckardt supposes, but rather syntactic. More specifically, the proposal is that the focus requirement corresponds to a distinctive DP internal syntactic structure that encodes DP internal focus-movement. In short, we propose that the internal move of the n-word to the PDP zone both encodes and satisfies the requirement for the focus marking characteristic of NPI, and at the same time provides a way to license a null $\mathrm{D}$ in NumP, which now fails to be licensed under number agreement.

For a brief clarification and justification of this view, let me quickly return to Kayne's (1994) discussion of the internal structure of possessives and other [de NP] structures in French. For constructions such as (63a), Kayne proposes the complex structure in (63b), which essentially exploits and expands the strong parallelism assumed to hold in generative perspectives between the internal structure of DP and the structure of sentences. Thus DP, on Kayne's view, contains a clause-like structure with an IP that is the complement of $d e$, here conceived as a complementizer equivalent in the nominal domain.

\section{(63) a. Le crayon de rouge}

b. [D [ DP/PP [NP crayon $\left.\left.]_{\mathrm{j}} d e\left[{ }_{\mathrm{IPP}}[\mathrm{AP} \text { rouge }]_{\mathrm{k}}\left[\mathrm{I}^{0}\left[\mathrm{FP}[\mathrm{NP}]_{\mathrm{j}}\left[\mathrm{F}^{0}[\mathrm{e}]_{\mathrm{k}}\right]\right]\right]\right]\right]\right]$ The construction in (63a) is derived as follows. The lowest part of the structure FP in (63b) is a kind of small clause, headed by $\mathrm{F}^{0}$, in which the adjective rouge is predicated of the NP crayon (in Spec FP at the start of the derivation). That is, FP is some kind of predicative structure akin to Le crayon est rouge 'The pen is red', but with a null copula. From this structure, there is first movement of the adjective rouge to Spec IP. This adjective movement is taken to be triggered by a focalization somewhat similar to what motivates predicate inversion in so-called 'inverse copular constructions' like 'the cause of the riot was a picture on the wall' (see Moro 1991). That is, the adjectival predicate rouge is 'focus-fronted', deriving a kind of inverse copular sentence, abstractly similar to 'tasty, this coffee', but here DP internal. Finally, the NP crayon also undergoes 
1 focus movement to the top of the structure, i.e, the specifier of $d e$, the 2 functional equivalent of $\mathrm{C}^{\mathrm{o}}$ in nominal structures. ${ }^{27}$

With this structure in hand, we can now return to our proposal concerning the internal structure of n-words and their syntactic and semantic evolution. In short, what we are proposing here is that, in the course of their evolution, the French n-words have undergone successive movements inside the structure of their nominal constituent that parallel the movements proposed by Kayne for the derivation of nominal structure like those in (63) above. Below is a sketch of the detail of this syntactic progression, as we see it:

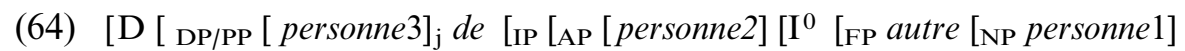
SDP PDP NP

For ease of reference in the following discussion, the respective positions of personne in the structure (64) have been labelled personne1, personne2, personne 3 in (64) and the correspondence with Zamparelli's proposed quantificational structure is given directly under it. At the bottom of the structure, 'personnel' is just a noun. Contingently (and thus optionally) at first, personne can undergo internal focus movement to Spec IP/PDP, the position of personne2, for emphasis. We propose to view the head $\mathrm{I}^{0} /$ PDP as some kind of null nominal functional projection, or null D, licensed under Spec-head gender/number agreement with the moved nominal personne. As a result of a gradual loss of gender and number features, agreement with this D is lost, so that movement to Spec IP/ PDP, i.e. personne2, comes to be licensed only under focus. This focus movement serves two purposes. First it structurally encodes the supposed lexical requirement for focus that Eckardt (2006) deems to be the hallmark of NPIs. Second, it licenses the null head of $\mathrm{I}^{0}$, now no longer licensed under agreement. It also has further interesting consequences. It syntactically crystallizes the change in the nature of the alternatives to which personne is now compared under emphatic negation. Following Eckardt, the semantic change is as in (63) above. Note that on this view, personne is now a predicate nominal akin to so called 'professional bare nouns' like priest. As a predicate nominal, it has become 'more adjectival' as it were, which could explain why it can undergo a focus movement that parallels that of adjectives such as rouge in Kayne's structure (63). We can speculate

27. For a discussion of these structures, see Kayne (2004: Chapter 8). 
1 that this movement to the higher position in the structure was optional at 2 first, becoming gradually obligatory later, to eventually lead to structural 3 reanalysis and direct merge/insertion of personne into this PDP specifier 4 position (personne2). This restructuring, in effect, grammaticalizes the focus 5 that Eckardt assumed to be a lexical requirement for NPIs. ${ }^{28}$ So in the 6 spirit of Eckardt (2006), but now as an internal structural construct, we 7 propose that it is the reanalysis of this focus movement in tune with the 8 pragmatic change in the focus-alternatives that eventually turns the former 9 noun personne into a dependent NPI, i.e. an intrinsically and internally 10 focused structure. Note of course, and this is crucial as it provides support 11 for this view, that the post-nominal position of autre at this stage of the structural change. It would not, in contrast, follow from any putative lexical requirement for focus. It is thus no accident, under our proposal, that the post-nominal position of autre coincides with an NPI interpretation of personne. In turn, we can take the post-nominal position of autre to signal the focalisation of personne that for Eckardt (2006) centrally defines what an NPI is.

It is time now to turn to the consideration of the final steps of the evolution of personne. In the final steps, personne reaches the highest position in the complex structure in (64), namely the position of personne3. This again, following Kayne (1994), involves a type of focus-movement. Here as well interesting consequences follow from this structural change. First, personne is predicted to precede the $\mathrm{C} / \mathrm{P}$ head $d e$, which accounts for its obligatory indirect modification by d'autre at this stage of its evolution. Furthermore as noted by Kayne, only elements that involve quantifica-

28. The analysis developed here suggests an exiting syntactic generalization for NPIs: only nominal structures that encode focus movement internal to DP of the sort discussed here can be NPIs. Note that this view provides a very interesting way to explain the semantic nature of phrasal NPIs like: qui que ce soit, literally 'who that this be'. Strictly speaking, these are grammaticalized (e.g. nominalized) instances of wh-movement to a focus position inside a structure that behaves like an NPI nominal. In contrast with characteristic lexical minimizers or generalizers that have been assumed to crosslinguistically provide good semantic source for NPI, these have none of the favoring semantics. Why they should provide such common source of NPI thus remained so far a bit of a mystery. The analysis provided here, resolves this mystery. These are such good NPI because they encode lexicalized focus movement in their internal structure. 
tion, in his terms an operator variable relation, can occupy this CP-like position. This suggests that it is only when moved to this highest position that personne acquires the full quantificational nature that is now associated with its negative meaning. Again, we can think of this movement as optional at first, explaining why indirect de modification of n-words for quite some time alternate with direct post-position modification. It then becomes - gradually - becomes more obligatory, before eventually leading to structural reanalysis.

Now, although our proposal provides quite a detailed account of how n-words have structurally and semantically acquired an NPI character in the course of their evolution, it still falls short of accounting for how they acquired their final intrinsic negative meaning. Somewhat disappointingly, Eckardt (2006), who provides such a deep and fascinating explanation of the semantic evolution of reinforcers into NPIs, does not in fact provide an interesting explanation for the acquisition of negative meaning. In her view, this comes about simply as a stylistic reanalysis. But what a stylistic reanalysis formally is, and what the exact compositional semantics of this final step entails, remains, unfortunately, far from clear. The structure we have proposed above, provides, perhaps, the beginning of an understanding of the mechanics of this final steps, but again, no precise semantic account will be offered here either. Note that in (63), personne3 is still dominated by a null determiner, which on Kayne's proposal is the Dhead that closes off the entire nominal relative clause like structure. Yet as amply discussed above, n-words, in contrast to NPIs, present no distributional limitation of occurrence. They appear free of any c-commanding operator and can comfortably occur even in a subject position. As was argued above, this shows that personne must eventually come to occupy the position of this higher $\mathrm{D}$, so that in effect, it comes to be incorporated into it, rather than being dominated by it. This incorporation in turn suggests a plausible pathway for understanding the negative meaning of personne. Conceivably, given contextual requirements on NPIs, this highest null D in the structure came to acquire a negative meaning. Perhaps as a precursory mid-step to this final change, personne and rien first became strong NPIs, licensed only in anti-veridical, i.e. strongly negative contexts. We can speculate that it would be on this step that the null determiner acquired a negative feature, as a sort of semantic encoding of this strong dependency on negation, i.e. a feature-sharing process encoding semantic rather than syntactic agreement. If so, personne would have come to inherit and intrinsically integrate this negative feature through its 
1 final incorporation into the highest null $\mathrm{D}$ in the structure (64). If correct, 2 note that this approach makes the interesting predictions that it is only 3 when nominal n-words occupy the highest position in their DP that they 4 could come to incorporate an essentially sentential negative feature. This 5 is interesting because, in the current syntactic framework of Minimalism, 6 the highest positions in constituents take on a particular status. They con7 stitute the edge of phases, i.e. the only positions from which access to a 8 higher domain of computation becomes possible. Within the Minimalist 9 framework, the notion of phase conceptually recalls that of encapsulated 10 domains. So the idea here is that to be visible from outside, the domain 11 of a particular phase, i.e. to be visible to a higher structural domain, a must not be properly contained within the boundaries of an encapsulated domain. This is in essence the core idea of Chomsky's PIC. Elements at the edge of a phase are visible to the next domain of computation. Elements contained within a phase are not. Within this framework, it becomes quite immediately obvious that structural change within a given domain can bring about visibility or invisibility to a higher domain of computation. It is this core idea that I wish to speculate could be at the basis of the correlated structural and semantic changes we have observed in the French n-words.

Applying this core idea to the case at hand, it would follow that the visibility of a negative feature, and hence its interpretability in a higher computational domain, here the sentence, should go hand in hand with its positioning at the edge of a domain. Suppose now that n-words were endowed with a negative feature from the onset of their development, perhaps for pragmatic reasons. If DP is a phase, an assumption that goes along with its similarity to $\mathrm{CP}$, then as long as this negative feature occurs within the DP domain, it will essentially remain un-interpretable from outside, i.e. here specifically, at the level of the sentential domain. So a sensible interpretation of this situation is that such a buried negative feature could not have sentential scope. In the gradual change of their internal structure, n-words have, through a series of internal movements, been brought closer to the edge of DP, and in effect, so has their negative feature. Once the DP edge was reached, it directly follows from the PIC that their negative feature became visible outside their nominal domain or in other words, visible to the sentential domain. In this new situation, their negative feature can now take on sentential scope, i.e. be interpretable at the sentential level. Schematically, the situation can be described as follows: 


$$
\begin{aligned}
& \text { (65) a. [TP f.... [DP .... [ F ] ] F invisible to higher domain } \\
& =\text { uninterpretable. } \\
& \text { b. }[\mathrm{TP} f . \ldots[\mathrm{DP} F[\ldots . .]] \text { edge } F \text { is visible to higher domain } \\
& =\text { interpretable }^{29}
\end{aligned}
$$

In (65a), $\mathrm{F}$ is invisible for sentence interpretation because it is inside the domain of D. From the perspective of a higher domain containing the $\mathrm{DP}$, the feature $\mathrm{F}$ is thus uninterpretable. In (64b) in contrast, because F is at the edge of the DP, in D head or D specifier, it becomes visible to the sentential domain, because it is part of this higher computation. Edges are always computed as part of their containing domain. This leads us to the following hypothesis:

(66) Feature Visibility principle:

The visibility/interpretability of a feature $\mathrm{F}$ relates to its position inside/at the edge of a domain of Computation

Or more technically:

(66') Feature interpretability $(\mathrm{uF} / \mathrm{iF})$ is governed by the PIC.

Within this theoretical frame, an interesting interpretation emerges for the structural changes we have observed. The hand in hand processes of structural change and semantic change we have brought evidence for here and before (Déprez and Martineau 2004) can be seen as part of a more general process of meaning change that is governed by very general principles of computation. ${ }^{30}$

\section{Conclusions}

To conclude, Jespersonian-inspired models such as Zeijlstra (2008) propose a macro-parametric approach to negative concord that locates the central factor dividing negative concord languages from non-negative

29. The question also arise within traditional accounts of grammaticalization since it is quite unclear in such a tradition how a semantic change from positive to negative could be considered as a form of semantic bleaching that is assumed to generally accompany grammaticalization.

30. For an application of the same principle, I call Visibility at the edge, see Déprez (2007, 2008) studies of the grammaticalization of number and specificity/ definiteness features in French Based Creole noun phrases. 
concord languages in the syntactic properties of the sentence negation operator. The micro-parametric approach proposed in this chapter, by contrast, takes negative concord to arise from a convergence of factors that depend largely on the structural and semantic make up of the negative dependent terms, the n-words. Such a convergence of factors may distinguish only a subset of expressions in a given language, permitting as a result inner language variations and historical changes that do not target all expressions in the same way. We have provided empirical arguments in favour of this approach showing that inner language diversity is found even in a seemingly uniform language such as Haitian Creole. Moreover, we have provided detailed empirical evidence of the complex structure of contemporary French n-words and in particular of the fact that they occupy a position at the highest level of their DP structure. We have furthermore demonstrated that the historical evolution of these n-words involved a change in their internal structure that goes hand in hand with correlated changes in the types of negative relation they are involved in, and we have charted the time course of these correlated changes. We have argued that these internal changes provide evidence for a stepwise rise of $n$-words inside the DP domain and have suggested that a negative feature becomes interpretable at the higher sentential domain only when it has reached the edge of the nominal structure. If correct, this proposal predicts that only n-words that occupy the highest structural level in DP could behave like intrinsically negative quantifiers, i.e. like quantified expressions whose negative interpretation has scope in the sentential domain. Finally, we have sketched a model of feature interpretability that captures these correlated changes and accounts for their effects through very general principles of computation.

\section{References}

\section{Sources}

Elicop http://bach.arts.kuleuven.be/elicop/

Frantext http://atilf.atilf.fr/frantext.htm

Textes de Francais Ancien http://www.lib.uchicago.edu/efts/ARTFL/projects/TLA/

\section{Studies}

Baker, Mark 2008

The macroparameter in a microparametric world. In: Theresa Biberauer (ed.), The limits of syntactic variation, 351-374. Amsterdam: Benjamins. 
Chomsky, Noam

2000 Minimalist inquiries: the framework. In: Roger Martin, David Michaels \& Juan Uriagereka (eds.), Step by step: Essays on minimalist syntax in honor of Howard Lasnik, 89-156. Cambridge: MIT Press.

Chomsky, Noam

2001 Derivation by phase. In: Michael Kenstowicz (ed.), Ken Hale: A

Cinque, Guglielmo life in language, 1-53. Cambridge: MIT Press.

1994 On the evidence for partial N-movement in the Romance DP. In: Guglielmo Cinque, Jan Koster, Jean-Yves Pollock, Luigi Rizzi and Raffaella Zanuttini (eds.), Paths Towards Universal Grammar. Studies in Honor of Richard S. Kayne, 85-110. Washington, 1994, Georgetown University Press.

Clas, André

1976 Matériaux pour l'étude du francais du Canada, Néologisme et canadianisme, vol 1. Montreal: Département de Linguistique, Université de Montréal.

Corblin, Francis, Viviane Déprez, Henriette de Swart \& Lucia Tovena

2004 Negative Concord. In: Francis Corblin \& Henriette de Swart (eds.), Handbook of French Semantics, 417-452. Stanford: CSLI.

Den Dikken, Marcel

1998 Predicate inversion in DP. In: Artemis Alexiadou \& Chris Wilder (eds.), Possessors, Predicates and Movement in the Determiner Phrase, 177-214. Amsterdam/Philadelphia: Benjamins.

Déprez, Viviane 1997 Two types of negative concord. Probus 9 (2): 103-142.

Déprez, Viviane 1999

The roots of negative concord in French and French-lexicon Creoles. In: Michel DeGraff (ed.), Language creation and language change: Creolization, diachrony, and development, 375428. Cambridge: MIT Press.

Déprez, Viviane 2000

Parallel (A)symmetries and the internal structure of negative expressions. Natural Language and Linguistic Theory 18: 253-342.

Déprez, Viviane 2003

Concordance négative, syntaxe des mots- $\mathrm{N}$ et variation dialectale. Cahier de linguistique française 25: 97-118.

Déprez, Viviane 2005

Morphological number, semantic number and bare nouns. Lingua 115 (6): 857-883.

Déprez, Viviane 2007

Probing the structuring role of grammaticalization: Nominal nonstituents in French lexifier Creoles. Journal of Pidgin and Creole Languages 22 (2): 263-307. 
1 Déprez, Viviane

On the structuring role of grammaticalized morpho-syntactic features. In: Emily Elfner, Martin Walkow (eds.), Proceeding of NELS 37, volume 1, 31-44. Booksurge LIc.

Déprez, Viviane \& France Martineau

2004 Micro-Parametric Variation and Negative Concord”. In: Julie Auger, J. Clancy Clements \& Barbara Vance (eds.), Contemporary Approaches to Romance Linguistics, 139-158. Amsterdam:

Eckardt, Regine Benjamins.

2006 Meaning change in grammaticalization. An enquiry into Semantic reanalysis. Oxford: Oxford University Press.

Giannakidou, Anastasia

1997 The landscape of polarity items. Ph.D. dissertation, University of Groningen.

Gougenheim, Georges

$1951 \quad$ Grammaire de la langue française du seizième siècle. Lyon: IAC.

Grevisse, Maurice

$1980 \quad$ Le bon usage. Paris: Duculot.

Huot, Hélène

$1981 \quad$ Construction infinitives du français. Le subordonnant de. Geneva: Droz.

Haegeman, Liliane \& Rafaella Zanuttini

$1991 \quad$ Negative heads and the Neg criterion. The Linguistic Review 8: 233-151.

Hazael-Massieux, Marie-Christine

2008 Textes anciens en créole français de la Caraïbe: Histoire et analyse. Paris: Publibook.

Herburger, Elena

2001 The negative concord puzzle revisited. Natural Language Semantics 9 (3): 289-333.

Kadmon, Nirit and P. Landman

$1993 \quad$ Any. Linguistics and Philosophy 16 (4): 353-422.

Kayne, Richard

$1977 \quad$ Syntaxe du francais, Paris: Seuil.

Kayne, Richard

1994 The antisymetry of syntax. Cambridge: MIT Press.

Kiparsky, Paul \& Cleo Condoravdi

2006 Tracking Jespersen's cycle. In: Mark Janse, Brian D. Joseph \&

Angela Ralli (eds.), Proceedings of the Second International

Conference on Modern Greek Dialects and Linguistic Theory,

Larson, Richard

172-197. Mytilene: Doukas.

1985 Bare-NP adverbs. Linguistic Inquiry 14: 595-621 

Larrivée, Pierre
2004

L'association négative: depuis la syntaxe jusqu'à l'interprétation. Geneva: Droz.

Martineau, France \& Viviane Déprez

2004 Pas rien/Pas aucun en français classique. Variation dialectale et historique. Langue francaise 143: 33-47.

Martineau, France \& Raymond Mougeon

2003 A sociolinguistic study of the origins of ne deletion in European

May, Robert

1989 Interpreting Logical Form. Linguistics and Philosophy 12: 387 435.

Pereltsvaig, Asya

$2006 \quad$ Small nominals. Natural Language \& Linguistic Theory 24: 433500 .

Penka, Doris

2006

A crosslinguistic perspective on n-words. Proceedings of BIDE05, International Journal of Basque Linguistics and Philology (Forthcoming).

Postal, Paul

1966

On so-called pronouns in English. In: David Reibel and Sanford Schane (eds.), Modern Studies in English, 201-223. Englewood Cliffs: Prentice Hall.

Postal, Paul M.

$2004 \quad$ Skeptical linguistic essays. Oxford: Oxford University Press.

Progovac, Ljiliana

1994

Negative and positive polarity: A binding approach. Cambridge:

Cambridge University Press.

Moro, Andrea 1991

Rooth, Mats

1985

The raising of predicates: copula, expletives and existence. In:

Lisa L. Cheng and Hamida Demirdash (eds.), MIT working Papers in Linguistics 15. More papers on wh-movement, 183218. Cambridge: Department of Linguistics and Philosophy, MIT.

Association with Focus. Ph.D. dissertation, University of Massachusetts Amherst.

Sarre, Nguissaly 2003

Diachronie des pronoms indéfinis à base nominale du moyen français au français classique: Les rémanences d'un emploi nominal à travers un emploi pronominal. Revue de Linguistique Romane 265-266: 117-136.

Sleeman, Petra 1996

Licensing empty nouns in French. Ph.D. dissertation, University of Amsterdam. 


\section{Roberts, Ian \& Anna Roussou}

2003 Syntactic change. A minimalist approach to grammaticalization. Cambridge: Cambridge University Press.

de Swart, Henriëtte \& Ivan A. Sag

2002 Negation and negative concord in Romance. Linguistics and Philosophy 25 (4): 373-417.

Watanabe, Akira

2004 The genesis of negative concord: Syntax and morphology of negative doubling. Linguistic Inquiry 35 (4): 559-612.

Tovena, Lucia, Viviane Déprez \& Jacques Jayez

2004 Polarity sensitive items. In: Francis Corblin \& Henriette de Swart (eds.), Handbook Of French Semantics, 391-417. Stanford: CSLI.

Zamparelli, Roberto

1995 Layers in the Determiner Phrase. Ph.D. dissertation, University of Rochester.

Zanuttini, Rafaella

1991 Syntactic properties of sentential negation: A comparative study of Romance languages. PhD dissertation, University of Pennsylvania.

Zeijlstra, Hedde

2004 Sentential negation and negative concord. Ph.D. Thesis, University of Amsterdam.

Zeijlstra, Hedde 2008

Negative concord is syntactic agreement. MS, University of Amsterdam. 